\title{
Influence of Alumina Precursor Properties on Cu-Fe Alumina Supported Catalysts for Total Toluene Oxidation as a Model Volatile Organic Air Pollutant
}

\author{
Tadej Žumbar ${ }^{1,2}$, Alenka Ristić ${ }^{1}{ }^{(}$, , Goran Dražić ${ }^{1}$, Hristina Lazarova ${ }^{3}$, Janez Volavšek ${ }^{1}$, Albin Pintar ${ }^{1}$ (1), \\ Nataša Zabukovec Logar ${ }^{1,4}$ and Nataša Novak Tušar ${ }^{1,4, *}$ \\ 1 National Institute of Chemistry, Hajdrihova 19, SI-1001 Ljubljana, Slovenia; Tadej.Zumbar@ki.si (T.Ž.); \\ alenka.ristic@ki.si (A.R.); goran.drazic@ki.si (G.D.); janez.volavsek@ki.si (J.V.); albin.pintar@ki.si (A.P.); \\ natasa.zabukovec@ki.si (N.Z.L.) \\ 2 Faculty of Chemistry and Chemical Technology, University of Ljubljana, Večna pot 113, \\ SI-1000 Ljubljana, Slovenia \\ 3 Institute of Organic Chemistry with Centre of Phytochemistry, Bulgarian Academy of Sciences, Acad. G. \\ Bonchev Str., Bl. 9, BG-1113 Sofia, Bulgaria; hristina.lazarova@orgchm.bas.bg \\ 4 Graduate School, University of Nova Gorica, Vipavska 13, SI-5000 Nova Gorica, Slovenia \\ * Correspondence: natasa.novak.tusar@ki.si
}

Citation: Žumbar, T.; Ristić, A.; Dražić, G.; Lazarova, H.; Volavšek, J.; Pintar, A.; Zabukovec Logar, N.; Tušar, N.N. Influence of Alumina Precursor Properties on $\mathrm{Cu}-\mathrm{Fe}$ Alumina Supported Catalysts for Total Toluene Oxidation as a Model Volatile Organic Air Pollutant. Catalysts 2021, 11, 252. https:// doi.org/10.3390/catal11020252

Academic Editors: Albin Pintar,

Nataša Novak Tušar and

Günther Rupprechter

Received: 6 January 2021

Accepted: 8 February 2021

Published: 13 February 2021

Publisher's Note: MDPI stays neutral with regard to jurisdictional claims in published maps and institutional affiliations.

Copyright: () 2021 by the authors. Licensee MDPI, Basel, Switzerland. This article is an open access article distributed under the terms and conditions of the Creative Commons Attribution (CC BY) license (https:// creativecommons.org/licenses/by/ $4.0 /)$.

\begin{abstract}
The structure-property relationship of catalytic supports for the deposition of redox-active transition metals is of great importance for improving the catalytic efficiency and reusability of the catalysts. In this work, the role of alumina support precursors of $\mathrm{Cu}-\mathrm{Fe} / \mathrm{Al}_{2} \mathrm{O}_{3}$ catalysts used for the total oxidation of toluene as a model volatile organic air pollutant is elucidated. Surface characterization of the catalysts revealed that the surface area, pore volume and acid site concentration of the alumina supports are important but not the determining factors for the catalytic activity of the studied catalysts for this type of reaction. The determining factors are the structural order of the support precursor, the homogeneous distribution of the catalytic sites and reducibility, which were elucidated by XRD, NMR, TEM and temperature programed reduction (TPR). $\mathrm{Cu}-\mathrm{Fe} / \mathrm{Al}_{2} \mathrm{O}_{3}$ prepared from bayerite and pseudoboehmite as highly ordered precursors showed better catalytic performance compared to $\mathrm{Cu}-\mathrm{Fe} / \mathrm{Al}_{2} \mathrm{O}_{3}$ derived from the amorphous alumina precursor and dawsonite. Homogeneous distribution of $\mathrm{Fe}_{\mathrm{x}} \mathrm{O}_{\mathrm{y}}$ and $\mathrm{CuO}_{\mathrm{x}}$ with defined $\mathrm{Cu} / \mathrm{Fe}$ molar ratio on the $\mathrm{Al}_{2} \mathrm{O}_{3}$ support is required for the efficient catalytic performance of the material. The study showed a beneficial effect of low iron concentration introduced into the alumina precursor during the alumina support synthesis procedure, which resulted in a homogeneous metal oxide distribution on the support.
\end{abstract}

Keywords: alumina precursors; $\mathrm{Cu}-\mathrm{Fe} / \mathrm{Al}_{2} \mathrm{O}_{3}$ catalysts; heterogeneous catalysis; nanostructures; toluene total catalytic oxidation

\section{Introduction}

Volatile organic compounds (VOCs) are classified, together with particulate matter, $\mathrm{NO}_{\mathrm{x}}, \mathrm{SO}_{\mathrm{x}}$, carbon monoxide and ammonia, as major or primary air pollutants with direct emission to the atmosphere and subsequent harmful effects [1]. For industrial sources, where the operating conditions of the treated flue gas streams include relatively low temperatures, higher flow rates and low pollutant concentrations, abatement with catalytic oxidation technique is a preferred choice [2,3]. There are two main groups of catalysts for VOC oxidation reactions: noble metal and non-noble metal catalysts. The former generally require lower operating temperatures, but their cost, their tendency to poisoning in the presence of sulphur compounds, and their geographical distribution, are the main reasons why the non-noble metals or transition metal oxides come into play $[4,5]$.

Bimetallic transition-metal supported catalysts are getting more and more attention as the synergistic effect with numerous beneficial properties are being discovered in different 
fields of catalysis, when two metals or metal oxides are combined in appropriate ratio [6,7]. Copper oxide is acknowledged as a prosperous catalyst for catalytic oxidation reaction and its catalytic properties were tested on various supports $[8,9]$. Our group previously showed that a catalyst consisting of a disordered mesoporous silica support with high interparticle mesoporosity $\left(600 \mathrm{~m}^{2} / \mathrm{g}\right)$, enables homogeneous dispersion of the active sites and provides good stability for loaded active transition metals [10]. We found out that the promotion of catalytic oxidation of toluene as a model VOC was due to the cooperative redox effect between $\mathrm{CuO}$ nanocrystals and finely dispersed $\mathrm{Cu}-\mathrm{oxo}-\mathrm{Fe}$ nanoclusters with defined $\mathrm{Cu} / \mathrm{Fe}$ molar ratio required for the synergistic effect. The mentioned $\mathrm{Cu}-\mathrm{Fe}$ silica supported catalyst is considered as a promising catalyst for the total oxidation of toluene as a model VOC in the temperature range from 320 to $380^{\circ} \mathrm{C}$ [11]. The simultaneous presence of $\mathrm{Cu}^{+} / \mathrm{Cu}^{2+}$ and $\mathrm{Fe}^{2+} / \mathrm{Fe}^{3+}$ species in the catalyst provides easier oxygen release, essential for the Mars-van Krevelen mechanism [12,13], widely accepted in the literature for this type of reaction. The mechanism of oxidation suggests the adsorption of VOC molecule on the catalyst surface, its oxidation with lattice oxygen following the oxidation of the reduced catalysts. The process of adsorption of toluene molecules can be affected by the surface properties of the catalysts. Activity in the total oxidation of VOC is connected with the interaction of aromatic electrons with metal ions in tetrahedral position, acting as Lewis acid sites, increasing the possibility of electrophilic attack of adsorbed oxygen and combustion of toluene molecules $[12,13]$. Catalysts based on $\mathrm{Cu}$ and $\mathrm{Fe}$ on alumina or other supports for oxidation of toluene have been already investigated [9,14-17], focusing mainly on catalyst performance and metal oxide structure. Copper proved to be the most active metal among several transition metals $(\mathrm{Cr}, \mathrm{Co}, \mathrm{Mo}, \mathrm{Ni}, \mathrm{Mn}, \mathrm{Fe}, \mathrm{Cu})$ on alumina support tested, with the optimum concentration being more than $5 \mathrm{wt} \%$ and less than $9 \mathrm{wt} \%$ [17]. $\mathrm{Cu}$ and $\mathrm{Mn}$ based catalysts prepared with commercial alumina impregnation with the corresponding copper and manganese salts, performed better than individual metal oxides [14] and when $\mathrm{Cu}$ and Fe were mixed together, the ratio was best in favor of copper 4 to 1 [15]. Loading $5 \mathrm{wt} \% \mathrm{Cu}$ oxide on commercial alumina support showed the best performance compared to other transition metal oxides [18,19], with the addition of manganese even improving the catalytic properties [16]. Alumina $\left(\mathrm{Al}_{2} \mathrm{O}_{3}\right)$ is one of the most commonly used materials in areas such as refractories, ceramics, abrasives, electronics etc., as well as in fields such as adsorption or in catalysis [20]. It exists in a variety of different crystal structures, of which $\gamma, \alpha, \theta$, and $\rho$ are the most commonly used. In supported catalysts, $\gamma-\mathrm{Al}_{2} \mathrm{O}_{3}$ support is often described as robust, thermally stable, easy to shape and offers many favourable surface properties such as high specific surface area $\left(100-400 \mathrm{~m}^{2} / \mathrm{g}\right)$, tendency to disperse the active phase, and acid-base properties [21-23]. These advantages, together with its moderate price, put alumina high on the list of used catalyst supports. Under isothermal conditions, the alumina surface consists of very stable $\mathrm{OH}$ groups, Lewis acid sites and acid-base pairs with high polarity. Active species loaded on alumina seem to distribute well due to surface defects, corners and edges of the support. If additional species are present during loading, they help to improve catalyst performance [21].

Aluminas are prepared from aluminum precursors (aluminum hydroxides, chlorides, sulfates, dawsonites etc.) by thermal treatment (calcination) above $300^{\circ} \mathrm{C}$ [20] and consequently, their surface properties and morphology depend mainly on their precursor properties [24,25]. Many techniques for the preparation of aluminum precursors are known $[20,21,24]$. Further focus is on different aluminas deriving from pseudoboehmite (also known as microcrystalline boehmite [24]), bayerite, amorphous alumina and dawsonite structures. The former is a representative of aluminum oxide hydroxides and is often used as a catalyst support due to its typically high surface area and pore volume $\left(>200 \mathrm{~m}^{2} / \mathrm{g},>0.4 \mathrm{~cm}^{3} / \mathrm{g}\right.$ ) [21]. Bayerite or $\alpha-\mathrm{Al}(\mathrm{OH})_{3}$ is an aluminum hydroxide which is commercially much less important than gibbsite $\left(\gamma-\mathrm{Al}(\mathrm{OH})_{3}\right)$ or boehmite $(\gamma-\mathrm{AlOOH})$. Dawsonite is a naturally occurring mineral composed of aluminum carbonate hydroxide with the general formula $\mathrm{MAlCO}_{3}(\mathrm{OH})_{2}\left(\mathrm{M}=\mathrm{Na}, \mathrm{K}, \mathrm{NH}_{4}\right.$, etc.), which can be synthesized to produce synthetic form with the desired alkali metal. According to the literature, 
calcination of dawsonite results in alumina or other oxide compounds with excellent component dispersion, porosity, thermal stability and catalytic performance for some reactions $[26,27]$. Bayerite and pseudoboehmite are mainly synthesized with a neutralization precipitation reaction or a sol-gel process, where $\mathrm{pH}$ value, aging time or temperature are crucial for the production of the desired phase. Sol-gel processes produce very pure materials when aluminum alkoxides are used as raw materials, but their main disadvantages are environmental and economic issues. In synthesis with precipitation using aluminum salt, purity is of paramount importance, as the residues of salts are often trapped in the bulk material. This can be avoided by careful handling and appropriate synthesis conditions $[20,21,24]$. Synthetic dawsonite is produced by reaction of aluminum hydroxide with $\mathrm{MHCO}_{3}\left(\mathrm{M}=\mathrm{Na}, \mathrm{K}, \mathrm{NH}_{4}\right.$, etc. $)$ at elevated temperatures and introduction of carbonic acid into a solution containing $\mathrm{Al}$ and $\mathrm{M}$ species or carbon dioxide in basic aluminum solution at elevated pressure [28].

In this work, we investigated aluminum oxide (alumina) as a support of bimetallic $\mathrm{Cu}-\mathrm{Fe}$ species, due to its relatively low production costs, compared to those with disordered mesoporous silicas with interparticle mesoporosity. One focus has been on the influence of alumina support preparation procedure and its properties on the activity of $\mathrm{Cu}$-Fe loaded catalysts for the oxidation of toluene in gas stream. By best of our knowledge, not many studies exist [29-31] in this topic that look into support-metal relationships when alumina supports with different characteristics are used. The other driving force was previously gained knowledge on promising catalytic behavior of $\mathrm{Cu}$-Fe containing mesoporous silica, where a synergistic redox effect of formed $\mathrm{CuO}(20 \%$ fraction) and $\mathrm{Cu}-\mathrm{Oxo}-\mathrm{Fe}$ clusters ( $80 \%$ fraction) with defined $\mathrm{Cu} / \mathrm{Fe}=11$ molar ratio was observed [11]. The endeavor of this work has been to synthesize various aluminum hydroxides as precursors for bimetallic $\mathrm{Cu}-\mathrm{Fe}$ catalysts on alumina supports with $\mathrm{Cu} / \mathrm{Fe}=11$ molar ratio, required for the redox effect and to study the structure-property-performance relationship of such catalysts for the total toluene gas phase oxidation reaction. We used different structural characterization techniques such as XRD, SEM, nitrogen physisorption, elemental analysis, TPR, UV-Vis and IR spectroscopies, NMR and TEM, to evaluate and explain the influence of the alumina support on the efficiency of catalysts. Reused samples were not characterized due to the focus of this study on the iron containing alumina precursors and their influences on the distribution of iron and copper active sites.

\section{Results}

\subsection{Characterization of the Catalysts Presursors and Catalysts}

Different alumina supports were prepared with presence of iron species, using different alumina precursors and techniques, which led to differences in the structure of supports' precursors-aluminum hydroxides and dawsonite. When exposed to temperatures above $300^{\circ} \mathrm{C}$, changes in chemical composition start to occur which subsequently led to transformation of alumina, with $\gamma-\mathrm{Al}_{2} \mathrm{O}_{3}$ forming at around $500{ }^{\circ} \mathrm{C}$, being the most desirable form as it offers the highest specific surface area and other favorable surface characteristics [22]. Its properties are mainly dependent on the properties of the hydroxide from which they are transformed and therefore differences can be expected.

\subsubsection{X-ray Diffraction}

X-ray diffraction analysis of alumina precursors shows distinct forms of bayerite or $\alpha-\mathrm{Al}[\mathrm{OH}]_{3}$ (PDF 00-020-0011) in the case of samples " $\mathrm{N}$ " and "b-O", pseudoboehmite or $\mathrm{AlO}[\mathrm{OH}]$ (reference pattern-PURAL ${ }^{\circledR}, \mathrm{SASOL}$ ) in samples "p-AS" and "p-N" and dawsonite (PDF 00-019-1175) in sample " $d$ ". Figure 1 displays XRD patterns with characteristic peaks of individual forms presented schematically above an individual pattern. Some additional peaks were detected in sample " $\mathrm{d}$ " and assigned to crystalline aluminum hydroxide phase called gibbsite or $\gamma-\mathrm{Al}[\mathrm{OH}]_{3}$, which is the most widespread form of aluminum hydroxides found in nature and also produced as a synthetic material [20]. Red arrows displayed above the pattern of sample " $\mathrm{d}$ " represent the gibbsite peaks (PDF 00-033-0018). 
The cause of their origin is in the synthesis procedure as the neutralization of sodium aluminate by carbonic acid precipitates aluminum hydroxide as well and the presence of sodium carbonate also leads to dawsonite transformation into aluminum hydroxide form [27]. With the hydrothermal treatment of the mixture in abundance of carbon dioxide, sodium dawsonite begins to form. Some aluminum hydroxide particles are although rather irreversibly transformed into a more stable gibbsite form [24,32]. This could probably be optimized during synthesis with the adjustment of the retention time and/or rheology conditions in the pressure vessel, which remains to be investigated in future.

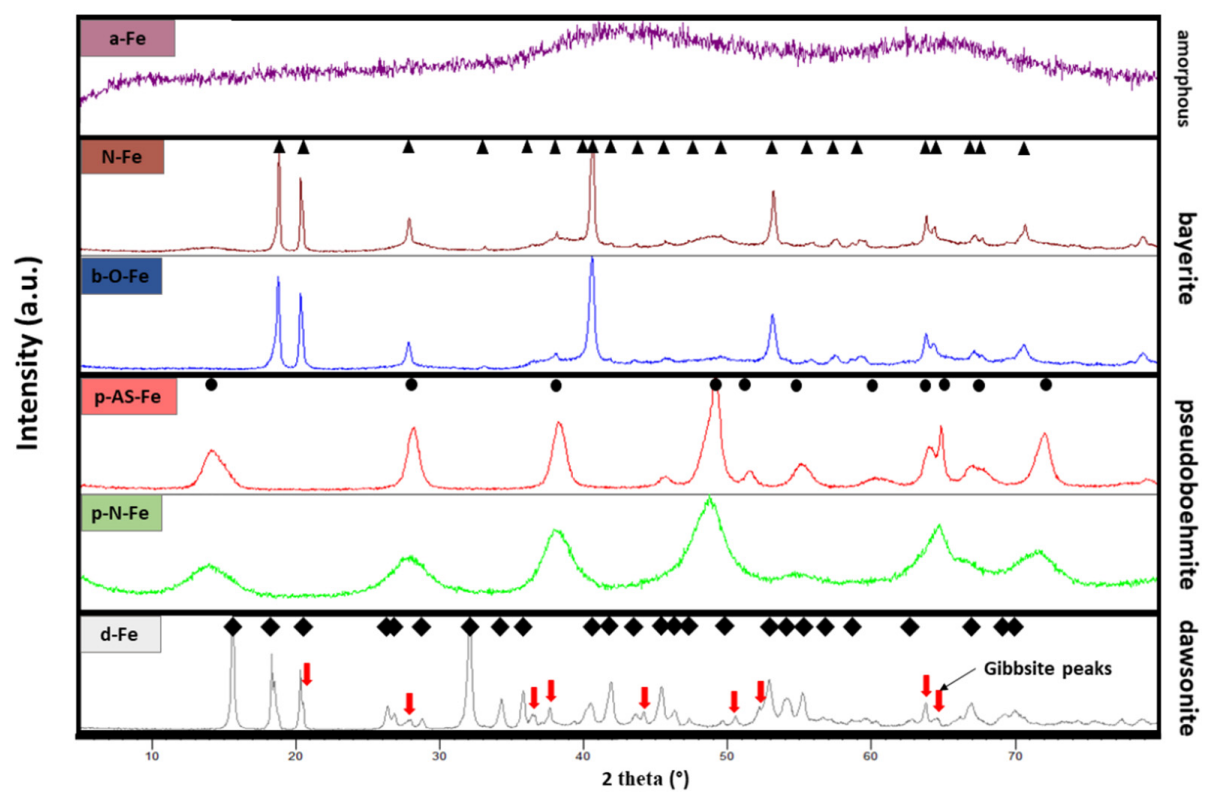

Figure 1. XRD patterns of synthesized iron-containing alumina precursors, indicating three distinct forms: bayerite $(\boldsymbol{\Lambda})$, pseudoboehmite $(\bullet)$ and dawsonite $(\diamond)$. Red arrows in the XRD patterns of sample »d « represent some additional detected peaks of gibbsite.

As described in the preparation procedure, all samples were synthesized in the presence of iron species. XRD pattern of iron-containing alumina precursor "a-Fe" shows a completely amorphous phase. When exposed to elevated temperatures, in this case $500{ }^{\circ} \mathrm{C}$ (Figure 2), the hydroxide starts to dehydrate and transform into a transition phase alumina [20]. That was also the case of calcined samples "N-Fe-500", "b-O-Fe-500", "p-ASFe-500" and "p-N-Fe-500". Patterns displayed in Figures 1 and 2 show no presence of iron oxides, Fe-Al spinel phases or any other plausible iron species, which could indicate their absence or that their size and quantity are below detection limits.

Their patterns (Figure 2) are characteristic for gamma $(\gamma)$ alumina transition form (PDF 00-050-0741). Sample "a-Fe-500" still displayed an XRD amorphous phase. This could be ascribed to the nature of the amorphous hydroxide transformation, where higher temperatures are often needed to achieve the same transformation stage in comparison to ordered hydroxide structures as starting materials for dehydration procedure [20,24]. It can be presumed that in this case thermal treatment at $500{ }^{\circ} \mathrm{C}$ does not suffice to order the structure of alumina into gamma form and that this would be achieved at even higher temperatures. Dawsonite-based iron-alumina sample "d-500" consists of gamma $(\gamma)$ alumina with additional peaks that were ascribed to dawsonite and sodium carbonate. It seems that the temperature transformation from dawsonite to alumina at $500^{\circ} \mathrm{C}$ was not sufficient to transform all of dawsonite to alumina phase. Sodium carbonate in this case is a side product of calcination of the $\mathrm{NaAlCO}_{3}[\mathrm{OH}]_{\mathrm{W}}$ form. To remove it, an additional washing step was applied at mild conditions to prevent any leaching of iron from the sample and to avoid any rehydration of the formed alumina and possibly formation of an unwanted phase [33]. The pattern suggests that not all of sodium carbonate was removed completely 
and some impurities remained. Based on the XRD patterns, calcination does not cause any differences in the presence of Fe species as they remain undetected by XRD.

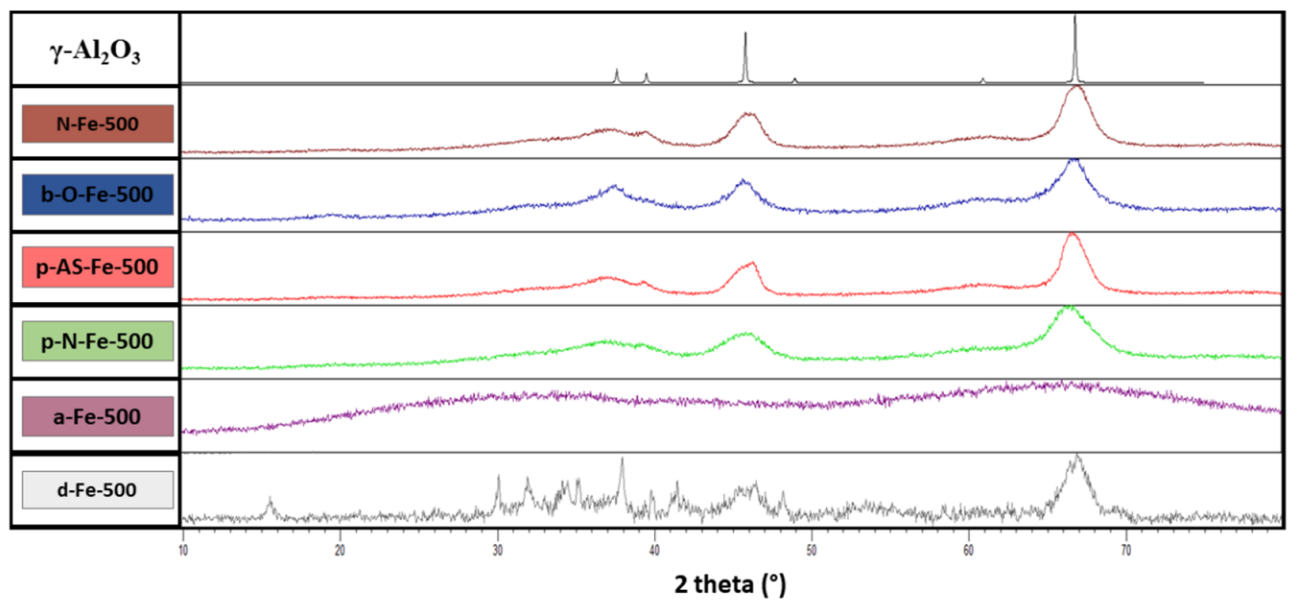

Figure 2. XRD patterns of calcined iron-containing alumina precursors. All samples except a-Fe-500 and d-Fe-500 are dehydrated and subjected to transformation to $(\gamma)$ alumina.

Figure 3 shows XRD patterns of calcined iron-containing alumina precursors impregnated with copper. In all cases except for sample "a-FeCu", transformation to gamma alumina $\left(\gamma-\mathrm{Al}_{2} \mathrm{O}_{3}\right)$ is visible with characteristic peaks at 37,46 and $67^{\circ} 2 \theta$. In the case of "a-FeCu", no distinct pattern was observed which can be contributed to an amorphous precursor and consequently to the insufficient dehydration temperature to achieve the transformation and arrangement of the structure to $\gamma-\mathrm{Al}_{2} \mathrm{O}_{3}$. It seems that the presence of excess water hinders the phase transformation [24,34]. In samples "p-N-FeCu", "p-AS$\mathrm{FeCu}$ " and "b-O-FeCu", no diffraction peaks characteristic for copper (I) or copper (II) oxides were visible, whereas for the sample "N-FeCu" two characteristic peaks assigned to $\mathrm{CuO}$ were visible at $35^{\circ}$ and $39^{\circ} 2 \theta$. The same goes for the sample " $\mathrm{d}-\mathrm{FeCu}$ " in which sodium nitrate impurities are also present $\left(29^{\circ}\right.$ and $\left.32^{\circ} 2 \theta\right)$. Those probably derived from reaction of sodium carbonate impurities and copper nitrate solution and the calcination step that followed.

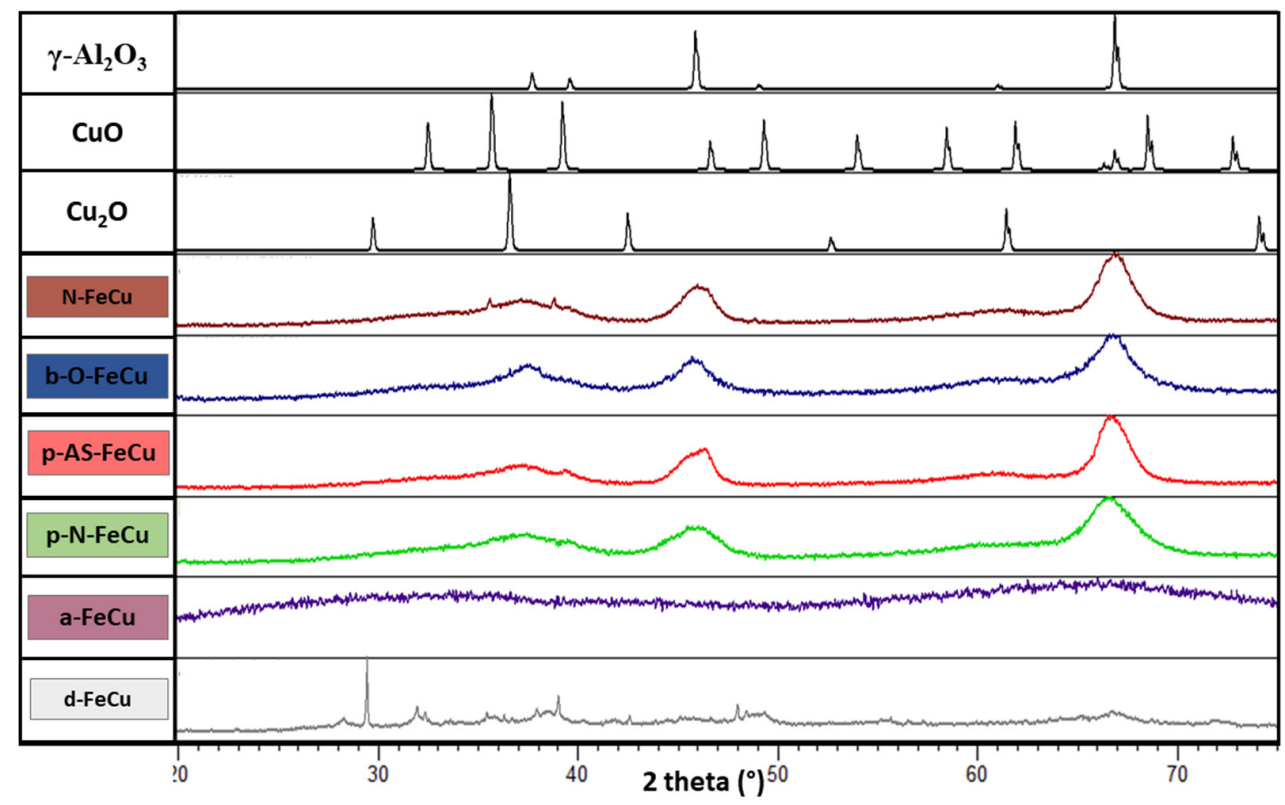

Figure 3. XRD patterns of calcined iron-alumina precursors impregnated with copper and reference patterns of $\gamma-\mathrm{Al}_{2} \mathrm{O}_{3}$ (PDF 00-050-0741), CuO (PDF 00-045-0937) and $\mathrm{Cu}_{2} \mathrm{O}$ (PDF 00-002-1067). 
As already mentioned, sample "N" derived catalyst was prepared with and without iron presence and studied in the same manner as other catalysts. As shown in Figure 4, structure of the precursor hydroxide (bayerite) does not change in the presence of iron species. Iron forms are also not detected after calcination and phase transformation to gamma alumina. Impregnation leads to formation of copper oxides, detected by XRD and TEM, which is apparently independent from iron, as in both cases (with and without $\mathrm{Fe}$ ) $\mathrm{CuO}$ particles are detected.

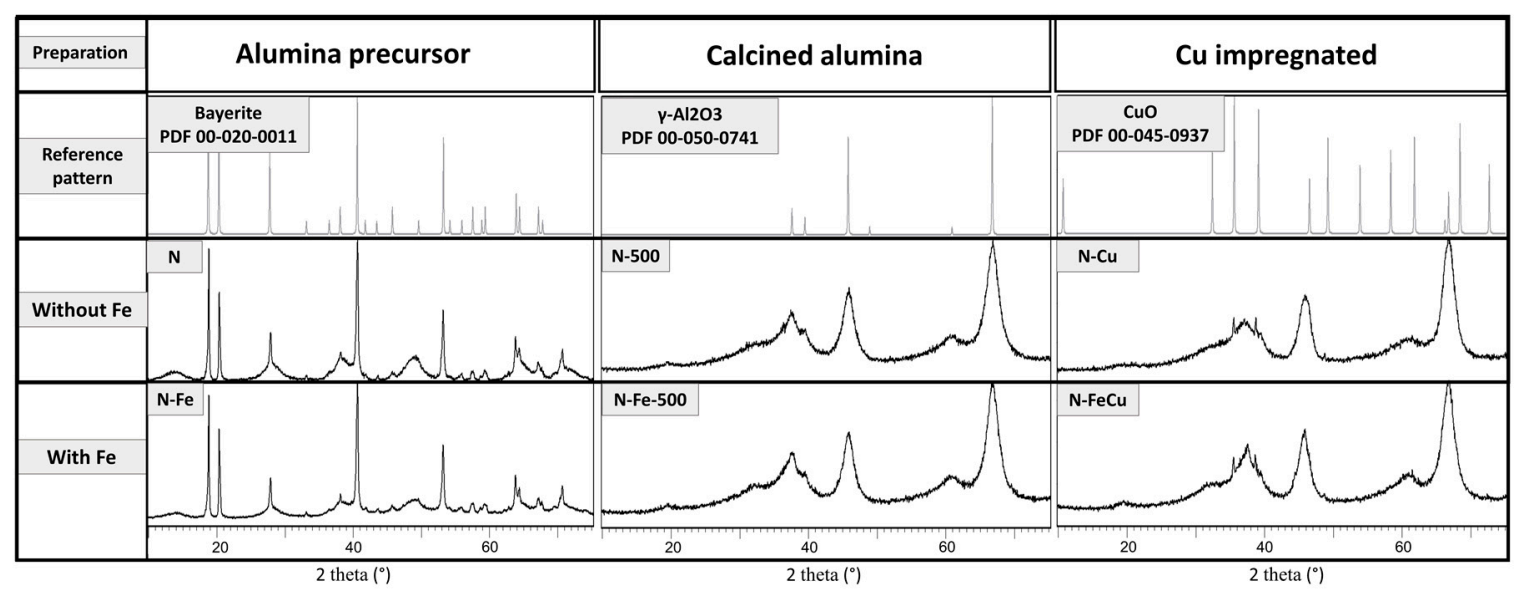

Figure 4. XRD patterns of alumina bayerite precursor " $\mathrm{N}$ " and alumina bayerite precursor with iron " $\mathrm{N}-\mathrm{Fe}^{\prime}$ (alumina precursor), calcined alumina "N-500" and calcined alumina with iron "N-Fe-500" (calcined alumina), Cu impregnated alumina "N-Cu" and $\mathrm{Cu}$ impregnated alumina with iron "N-FeCu" (Cu impregnated).

\subsubsection{SEM, Elemental Analysis, $\mathrm{N}_{2}$ Physisorption and Pyridine TPD}

Morphologies of the samples are distinctly different as the samples derive from various raw materials and different preparation procedures (Figure 5). The dawsonite derived sample "d-FeCu" has a needle-like morphology, sample produced from an amorphous alumina precursor, "a-FeCu", consists of round shape particles several nanometers in size. Bayerite derived samples "b-O-FeCu" and "N-FeCu" are built from nano-sized particles and no distinct morphology is visible with SEM. Pseudoboehmite originated samples "p-N$\mathrm{FeCu}$ " and "p-AS-FeCu" have interesting morphologies resembling very small nanosized plate-like particles. The former consist of a structure with large voids (several tens of nanometers in size) and individual particles are more defined and larger in size, whereas in case of latter they form an apparently rough surface and are smaller in size (couple of nanometers).
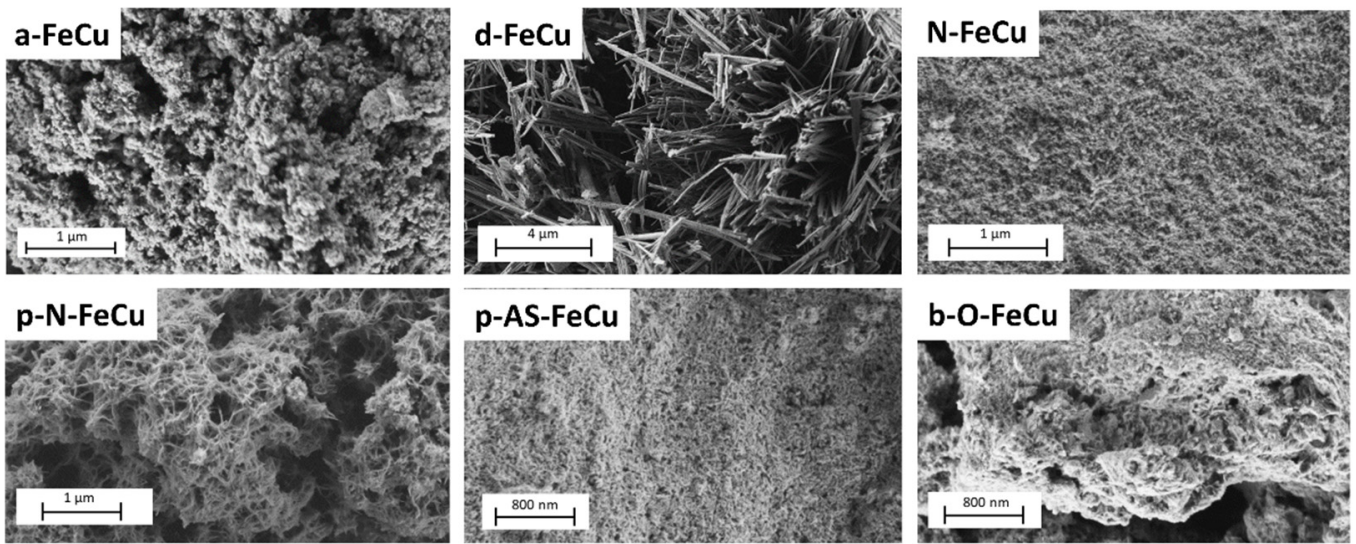

Figure 5. SEM images of the bimetal samples "a-FeCu”, "d-FeCu”, "N-FeCu”, "p-N-FeCu”," p-AS-FeCu” and "b-O$\mathrm{FeCu}$ ", exhibiting different morphologies of the prepared samples, which derive from different support structures and preparation procedures. 
Table 1 shows textural and surface properties determined by nitrogen physisorption (Supplementary Materials, Figure S2) and pyridine TPR (Supplementary Materials, Figure S3.1) together with catalytic activity (as percent of conversion) of the samples at 350 and $410{ }^{\circ} \mathrm{C}$. Decrease in specific surface area in Cu impregnated samples is noticed and expected due to the employed method of impregnation and the second calcination that follows. During that, also the pore diameter gets broader, from $5 \mathrm{~nm}$ to $4-6 \mathrm{~nm}$ in comparison to those without and with copper. An interesting observation is the acid site concentration decrease, when iron is introduced, from 0.8 to $0.68 \mu \mathrm{mol} / \mathrm{m}^{2}$, compensating the Lewis acidity of alumina after impregnation with copper, acid site concentration was significantly increased to $1.32 \mu \mathrm{mol} / \mathrm{m}^{2}$ in case of sample without iron and to $1.72 \mu \mathrm{mol} / \mathrm{m}^{2}$ when iron was present in the sample. Slightly stronger acid sites were present in "N-Cu" sample compared to the "N-FeCu" sample in the low temperature range below $300{ }^{\circ} \mathrm{C}$ (see Supplementary Materials, Figure S3.2).

Table 1. Brunauer-Emmett-Teller (BET) specific surface area $\left(\mathrm{S}_{\mathrm{BET}}\right)$, pore volume $\left(\mathrm{V}_{\mathrm{p}}\right)$, pore diameter $\left(d_{P}\right)$, concentration of acid sites ( $c_{A}$.S. $)$ and conversion of toluene at $350\left(c_{350}\right)$ and $410^{\circ} \mathrm{C}\left(c_{410}\right)$ (based on catalytic activity presented in chapter Catalytic properties) of "N-500", "N-Fe-500", "N-Cu" and "N-FeCu" samples.

\begin{tabular}{|c|c|c|c|c|c|c|c|}
\hline $\begin{array}{c}\text { Sample } \\
\text { Abbreviation }\end{array}$ & $\begin{array}{c}\mathrm{S}_{\mathrm{BET}} \\
\left(\mathrm{m}^{2} / \mathrm{g}\right)\end{array}$ & $\begin{array}{c}V_{P} \\
\left(\mathrm{~cm}^{3} / \mathrm{g}\right)\end{array}$ & $\begin{array}{c}d_{P} \\
(n m)\end{array}$ & $\underset{(\mathrm{mmol} / \mathrm{g})}{\mathrm{c}_{\text {A.S. }}}$ & $\underset{\left(\mu \mathrm{mol} / \mathrm{m}^{2}\right)}{\mathrm{c}_{\text {A.S. }}}$ & $\begin{array}{l}c_{350} \\
(\%)\end{array}$ & $\begin{array}{l}c_{410} \\
(\%)\end{array}$ \\
\hline $\mathrm{N}-\mathrm{FeCu}$ & 180 & 0.349 & $4-6$ & 0.3096 & 1.72 & 34 & 77 \\
\hline $\mathrm{N}-\mathrm{Cu}$ & 171 & 0.308 & $4-6$ & 0.2272 & 1.32 & 37 & 77 \\
\hline N-Fe-500 & 229 & 0.338 & 5 & 0.1554 & 0.68 & 13 & 19 \\
\hline N-500 & 221 & 0.353 & 5 & 0.1764 & 0.80 & / & / \\
\hline
\end{tabular}

Due to versatile alumina precursors and synthesis approaches, the differences between the samples in terms of textural properties (specific surface area, pore volume and pore size) and concentration of acid sites are expectable. As presented in Table 2, the highest Brunauer-Emmett-Teller (BET) [35] specific surface area of $286 \mathrm{~m}^{2} / \mathrm{g}$ as well as the highest pore volume of $1.11 \mathrm{~cm}^{3} / \mathrm{g}$ was determined for the sample " $\mathrm{p}-\mathrm{N}-\mathrm{FeCu}$ " formed from a pseudoboehmite precursor. This was unexpected since bayerite should exhibit the highest BET surface area $[20,35]$, due to structural and chemical characteristics. This sample had also the highest concentration of acid sites per gram of sample $(454 \mu \mathrm{mol})$. Samples "d$\mathrm{FeCu}$ " and "a-FeCu" exhibited the lowest pore volume, specific surface area and also the acid site concentration, which was in correlation to the catalytic performance of those two materials. They had the lowest conversions at 350 and $410{ }^{\circ} \mathrm{C}\left(c_{350}\right.$ and $\left.c_{410}\right)$ as $28-32 \%$ and $16-22 \%$, respectively.

Table 2. Textural $\left(\mathrm{S}_{\mathrm{BET}}, \mathrm{V}_{\mathrm{p}}, \mathrm{d}_{\mathrm{P}}\right.$; see Supplementary Materials, Figure $\mathrm{S} 2$ ) and surface properties (c $\mathrm{c}_{\mathrm{A} . \mathrm{S} ., ;}$ see Supplementary Materials, Figure S3) with catalytic activity as conversion at 350 and $410{ }^{\circ} \mathrm{C}\left(c_{350}\right.$ and $c_{410}$, based on catalytic activity presented in chapter Catalytic properties) of Cu-Fe containing samples.

\begin{tabular}{|c|c|c|c|c|c|c|c|c|}
\hline $\begin{array}{c}\text { Sample } \\
\text { Abbreviation }\end{array}$ & $\begin{array}{l}\text { Precursor } \\
\text { Structure }\end{array}$ & $\begin{array}{c}\mathrm{S}_{\mathrm{BET}} \\
\left(\mathrm{m}^{2} / \mathrm{g}\right)\end{array}$ & $\begin{array}{c}V_{P} \\
\left(\mathrm{~cm}^{3} / \mathrm{g}\right)\end{array}$ & $\begin{array}{c}d_{P} \\
(n m)\end{array}$ & $\begin{array}{c}\mathrm{c}_{\mathrm{A} . \mathrm{S}} \\
(\mu \mathrm{mol} / \mathrm{g})\end{array}$ & $\underset{\left(\mu \mathrm{mol} / \mathrm{m}^{2}\right)}{\left.\mathrm{c}_{\text {A }}\right)}$ & $\begin{array}{l}c_{350} \\
(\%)\end{array}$ & $\begin{array}{l}c_{410} \\
(\%)\end{array}$ \\
\hline a-FeCu & Amorphous & 45 & 0.102 & $>80$ & 136 & 3.01 & 28 & 32 \\
\hline $\mathrm{d}-\mathrm{FeCu}$ & Dawsonite & 26 & 0.103 & $/ 1$ & 47 & 1.81 & 16 & 22 \\
\hline $\mathrm{N}-\mathrm{FeCu}$ & Bayerite & 180 & 0.349 & $4-6$ & 310 & 1.72 & 34 & 77 \\
\hline $\mathrm{p}-\mathrm{N}-\mathrm{FeCu}$ & Pseudoboehmite & 286 & 1.110 & $13-63$ & 454 & 1.59 & 42 & 78 \\
\hline $\mathrm{p}-\mathrm{AS}-\mathrm{FeCu}$ & Pseudoboehmite & 178 & 0.549 & $19 ;>80$ & 239 & 1.34 & 38 & 80 \\
\hline $\mathrm{b}-\mathrm{O}-\mathrm{FeCu}$ & Bayerite & 225 & 0.274 & 3 & 324 & 1.41 & 34 & 84 \\
\hline
\end{tabular}

\footnotetext{
${ }^{1}$ no distinct pore size $\left(\mathrm{d}_{\mathrm{P}}\right)$ was detected in sample $\mathrm{d}-\mathrm{FeCu}$
} 
Steric restrictions for the toluene molecule were neglected in all samples as they all exhibit mesoporosity with pores larger than $2 \mathrm{~nm}$, or even macroporosity [35]. Such pores are easily accessible for the toluene molecule, being of approximately $0.58 \mathrm{~nm}$ in size.

\subsubsection{UV-Vis DR and FTIR Spectroscopies}

UV-Vis spectra of "N-Fe", "N-FeCu”, "p-AS-FeCu”, "p-N-FeCu”, “a-FeCu”, "d-FeCu” and "b-O-FeCu" samples are shown in Figure 6. The analysis of spectra belonging to "N$\mathrm{FeCu}$ ", "p-AS-FeCu”, "p-N-FeCu", "a-FeCu", "b-O-FeCu" and "d-FeCu" samples reveals $\mathrm{Fe}^{3+} / \mathrm{Cu}^{2+} \rightarrow \mathrm{O}$ charge-transfer (CT) bands between 200 and $300 \mathrm{~nm}$, which are usually assigned to isolated $\mathrm{Fe}^{3+}$ or $\mathrm{Cu}^{2+}$ ions [10,36-39]. Bands between 300 and $400 \mathrm{~nm}$ seen in all samples can be assigned to octahedral $\mathrm{Fe}^{3+}$ and $\mathrm{Cu}^{2+}$ in small oligomeric $\mathrm{Fe}_{\mathrm{x}} \mathrm{O}_{\mathrm{y}}[10,36]$ and $\mathrm{CuO}_{\mathrm{x}}$ clusters $[37,38]$, respectively. The shoulder at around $470 \mathrm{~nm}$ in the spectra of "N-Fe", "p-AS-Fe", "a-Fe" and "d-FeCu" samples is due to larger $\mathrm{Fe}_{2} \mathrm{O}_{3}$ nanoparticles [38,39], while the intensity of this band in the sample "p-N-Fe" is rather low, indicating the influence (as a consequence) of a different precursor preparation. Furthermore, the band between 600 and $850 \mathrm{~nm}$ corresponds to the $\mathrm{d}-\mathrm{d}$ transition of $\mathrm{Cu}^{2+}$ ions in an octahedral environment, which can be attributed to $\mathrm{CuO}$ nanoparticles $[38,40]$, is found in all $\mathrm{Cu}$ containing samples besides in the sample "d-FeCu". Furthermore, the shoulder at $580 \mathrm{~nm}$, which is typical for copper metal clusters [38,41,42], can be found only in the spectrum of sample " $\mathrm{d}-\mathrm{FeCu}$ ".

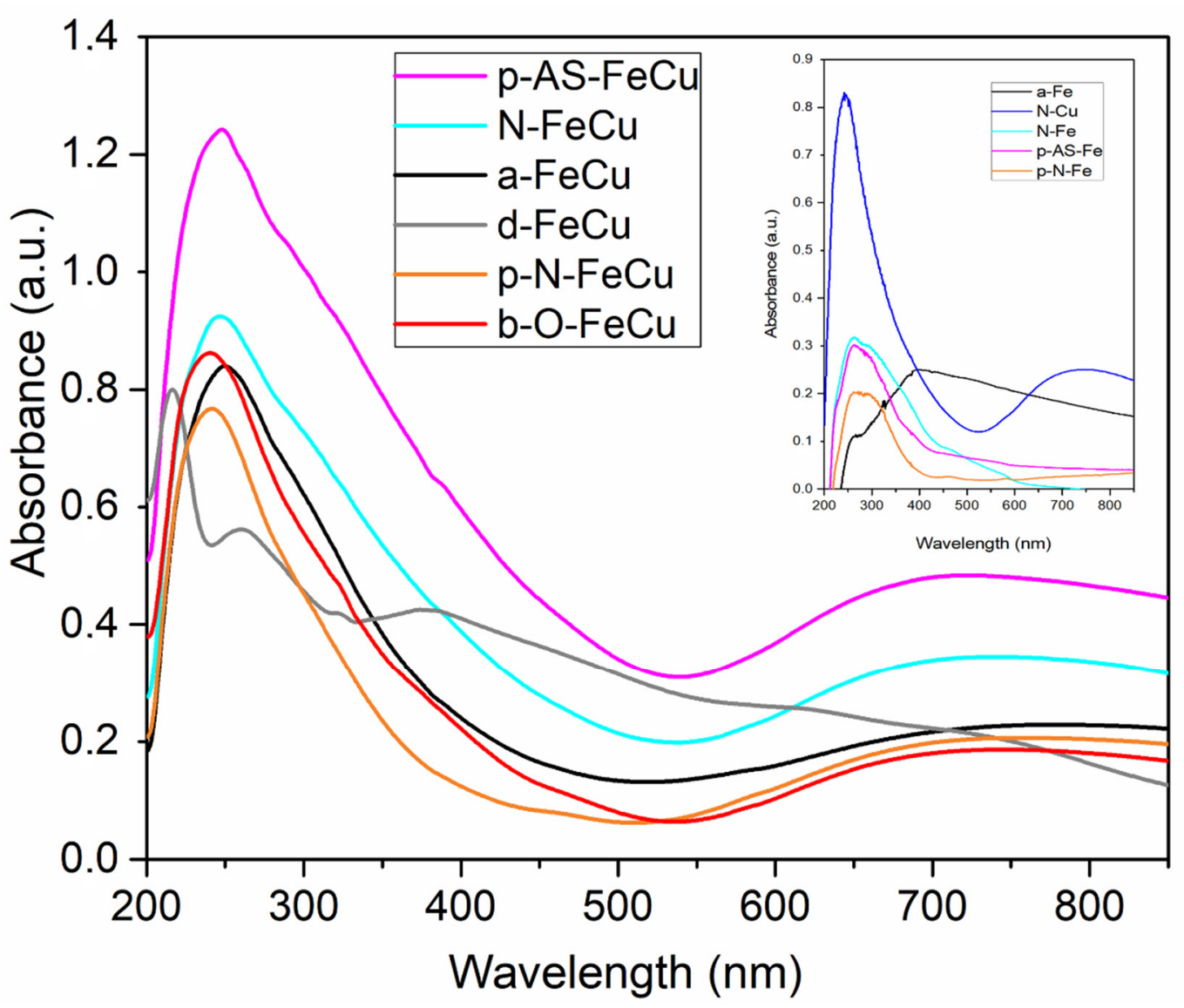

Figure 6. UV-Vis DRS (diffuse reflectance spectroscopy) spectra of FeCu samples and Fe alumina and Cu alumina samples in inserted graph.

Figure 7 shows skeletal FTIR-ATR (attenuated total reflection) spectra of $\mathrm{FeCu}$ samples. Typical IR spectra of $\gamma-\mathrm{Al}_{2} \mathrm{O}_{3}$ with a broad band at $510 \mathrm{~cm}^{-1}$ and two shoulders at 730 and $800 \mathrm{~cm}^{-1}$ can be observed for the samples "N-FeCu", "p-N-FeCu", "p-AS-FeCu" and "b-O-FeCu". The band at $510 \mathrm{~cm}^{-1}$ is assigned to $\mathrm{Al}-\mathrm{O}$ stretching in the octahedral units $\left(\mathrm{AlO}_{6}\right)[43,44]$, and the shoulders at 730 and $790 \mathrm{~cm}^{-1}$ are related to the symmetric 
stretching vibration of the $\mathrm{AlO}_{4}$ tetrahedron [43]. Due to overlapping of broad bands of $\gamma-\mathrm{Al}_{2} \mathrm{O}_{3}$ and $\mathrm{CuO}$, two bands of $\mathrm{CuO}$ at 480 and $534 \mathrm{~cm}^{-1}$ and shoulder at $580 \mathrm{~cm}^{-1}$ [45] are not seen in "N-FeCu", "p-N-FeCu", "p-AS-FeCu", "b-O-FeCu" and "a-FeCu" samples, while they can be observed in the spectrum of "d-FeCu" material. A shoulder at $470 \mathrm{~cm}^{-1}$ can be observed in "N-FeCu", "p-N-FeCu", "p-AS-FeCu" and "b-O-FeCu" samples, which can probably be due to $\mathrm{CuO}$ presence. The bands at $727 \mathrm{~cm}^{-1}, 847 \mathrm{~cm}^{-1}$ and $955 \mathrm{~cm}^{-1}$ and shoulders at $672 \mathrm{~cm}^{-1}$ and $952 \mathrm{~cm}^{-1}$ are assigned to dawsonite [46] in the spectrum of d-FeCu sample. The FTIR skeletal bands in the range of $400-900 \mathrm{~cm}^{-1}$ correspond to the $\mathrm{Al}-\mathrm{O}$ stretching related to the octahedral $\left(\mathrm{AlO}_{6}\right)$ and tetrahedral $\left(\mathrm{AlO}_{4}\right)$ units in the network of $\gamma-\mathrm{Al}_{2} \mathrm{O}_{3}$. Generally, infrared spectrum of $\gamma-\mathrm{Al}_{2} \mathrm{O}_{3}$ is characterized by two very broad poorly resolved bands in the medium IR region between 500 and $850 \mathrm{~cm}^{-1}$. It was reported that $\mathrm{Al}-\mathrm{O}$ stretching in $\mathrm{AlO}_{6}$ and $\mathrm{AlO}_{4}$ units was at around $500-750$ and $750-850 \mathrm{~cm}^{-1}$, respectively [43]. The peak position may change significantly depending on the preparation methods and existence of defects and dopants in the lattice of $\gamma-\mathrm{Al}_{2} \mathrm{O}_{3}$ [47].

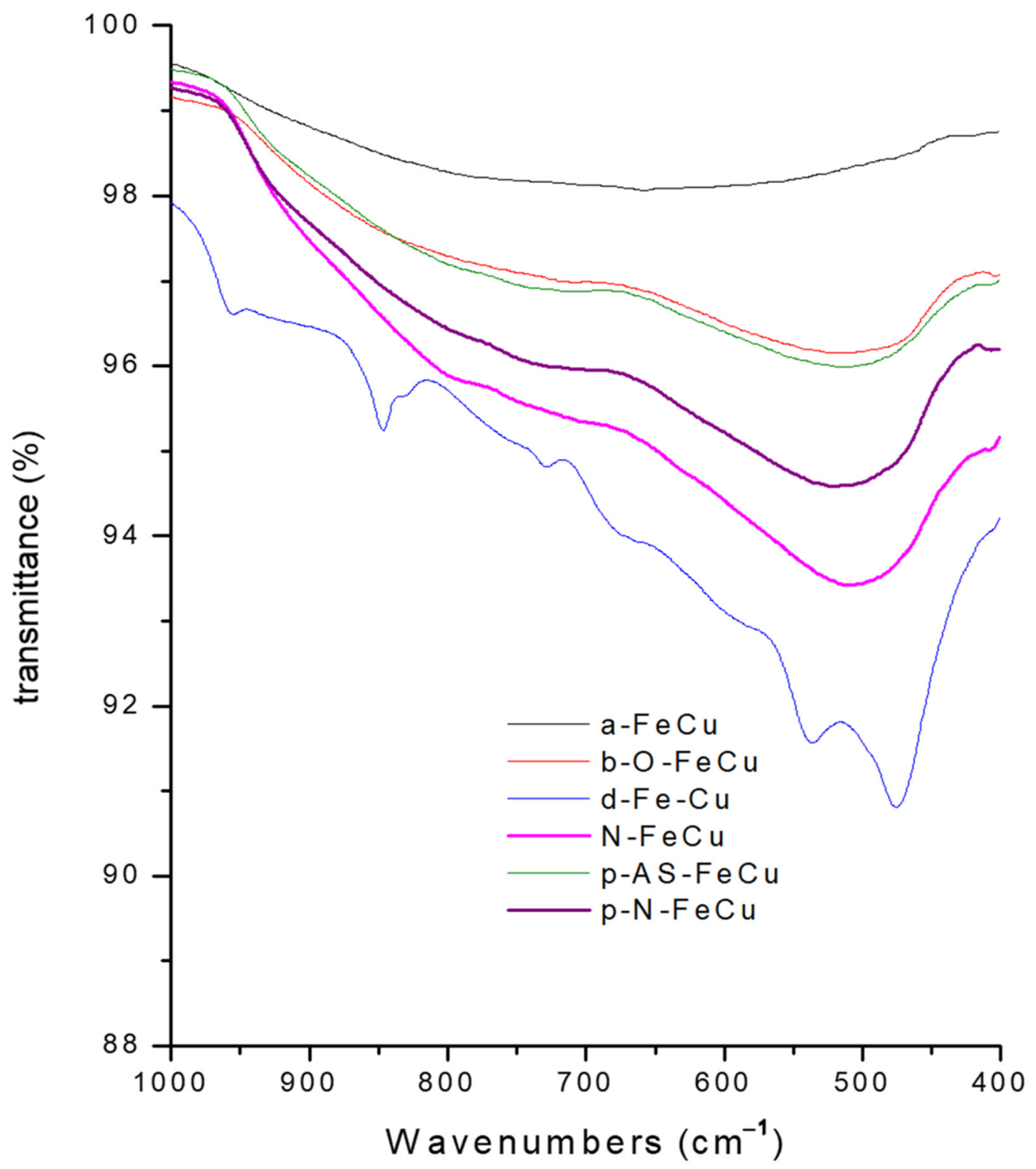

Figure 7. Acquired FTIR-ATR spectra of FeCu samples. 


\subsubsection{Al NMR Spectroscopy}

${ }^{27} \mathrm{Al}$ MAS NMR spectra of "N-FeCu", "p-AS-FeCu", and "b-O-FeCu" samples are typical for the $\gamma-\mathrm{Al}_{2} \mathrm{O}_{3}$ phase (Figure 8). They all exhibit a signal of $\mathrm{AlO}_{4}$ groups resonating at about $68 \mathrm{ppm}$ and a signal of $\mathrm{AlO}_{6}$ groups resonating at about $10 \mathrm{ppm}$, with relative abundancies of 0.30 and 0.70, respectively. As in the case of Samain et al. [48], they contain no or negligible amount of five-coordinated $\mathrm{Al}$ species. The spectrum of " $\mathrm{p}-\mathrm{N}-\mathrm{FeCu}$ " is slightly different from the previous three spectra; it does exhibit a weak contribution of $\mathrm{AlO}_{5}$ groups and a slightly different signal of $\mathrm{AlO}_{6}$ groups (see Supplementary Materials, Figure S4). The latter signal is probably a sum of two severely overlapped contributions, major one being typical for $\gamma-\mathrm{Al}_{2} \mathrm{O}_{3}$ and minor one belonging to alumina phase, characterized by the signal of $\mathrm{AlO}_{6}$ species that resonates at about $15 \mathrm{ppm}$ (potential candidate are $\delta$ and $\theta$-alumina whose $\mathrm{AlO}_{4}$ signals are expected to overlap with the corresponding signal of $\gamma-\mathrm{Al}_{2} \mathrm{O}_{3}$ and which are expected products during the transformation of $\gamma$-alumina to $\alpha$-alumina) [49]. However, the additional signals are very weak compared to the signals of $\gamma-\mathrm{Al}_{2} \mathrm{O}_{3}$, so it is expected that the properties of "p-N-FeCu" are not significantly different from the properties of "N-FeCu", "p-AS-FeCu", and "b-O-FeCu" samples. As opposed to that, the ${ }^{27} \mathrm{Al}$ MAS NMR spectrum of " $\mathrm{d}-\mathrm{FeCu}$ " exhibits markedly different relative intensities of the $\mathrm{AlO}_{4}$ and $\mathrm{AlO}_{6}$ signals. This is not surprising, considering that the XRD analysis already showed that this sample comprises $\gamma-\mathrm{Al}_{2} \mathrm{O}_{3}$ and non-negligible amount of dawsonite. The spectrum of "a-FeCu" is drastically different from ${ }^{27} \mathrm{Al}$ MAS NMR spectra of all other samples. Its broad signals, including a very strong one belonging to five-coordinated $\mathrm{Al}$ species, confirm the amorphous nature of this sample.

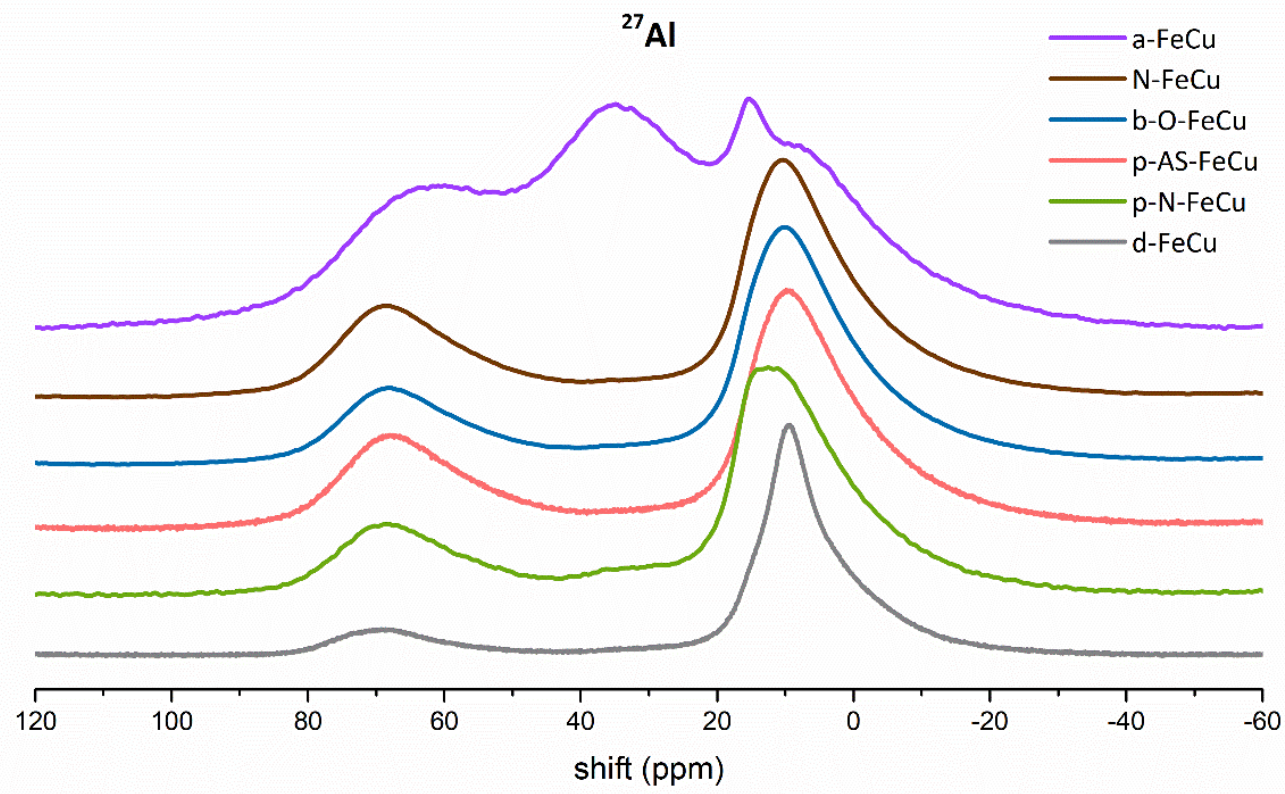

Figure 8. ${ }^{27} \mathrm{Al} \mathrm{NMR}$ spectra of $\mathrm{FeCu}$ samples.

\subsubsection{Temperature Programed Reduction $\left(\mathrm{H}_{2}-\mathrm{TPR}\right)$}

Temperature programed reduction with hydrogen was used to evaluate the reduction characteristics of supported $\mathrm{Cu}-\mathrm{Fe}$ catalyst samples. As presented in Figure 9, the samples have different reduction profiles. Reduction of samples "N-FeCu" and "p-AS-FeCu" starts at approximately 170, of sample "p-N-FeCu" at 210 and of sample "b-O-FeCu" at $190{ }^{\circ} \mathrm{C}$. Samples "a- $\mathrm{FeCu}$ " and "d-FeCu" start to reduce after 230 and $240{ }^{\circ} \mathrm{C}$, respectively. Sample "b-O-FeCu" displays a bimodal reduction profile with a shoulder on a high temperature side, indicating the presence of two different types of species that are present in the sample. The first reduction maxima is at $225^{\circ} \mathrm{C}$ and the second at $265^{\circ} \mathrm{C}$. Interesting is the reduction profile of the dawsonite derived catalyst " $\mathrm{d}-\mathrm{FeCu}$ ", which has a very steep end 
reduction profile indicating that the present species are being massively reduced at peak temperature. The hydrogen consumption in this case is also very high at $3.17 \mathrm{mmol} / \mathrm{g}$ of catalyst. Although these two parameters could indicate a catalytically active sample, the reduction peak temperature at $460^{\circ}$ indicates a strong metal-support interaction in this sample. Sample "a- $\mathrm{FeCu}$ " also displays a quite high reduction peak temperature that occurs at $310{ }^{\circ} \mathrm{C}$. The two samples of bayerite precursor, "b-O-FeCu" and "N-FeCu", together with the pseudoboehmite originating sample "p-AS-FeCu" have the reduction peaks at the lowest temperatures amongst all samples, ranging from 210 to $230^{\circ} \mathrm{C}$, whereas for the sample "p-N-FeCu" the reduction peak is at almost $250^{\circ} \mathrm{C}$. Reducibility of " $\mathrm{N}$ " sample series with and without presence of iron was also recorded (Supplementary Materials, Figure S5) and interestingly the reduction peak of the sample "N-Cu" prepared without iron, has a slight shoulder on the high temperature side. However, the samples prepared without presence of copper have poor reducibility (Supplementary Materials, Figure S5). The suggested reduction path in studied samples is the stepwise reduction of copper $2+$.

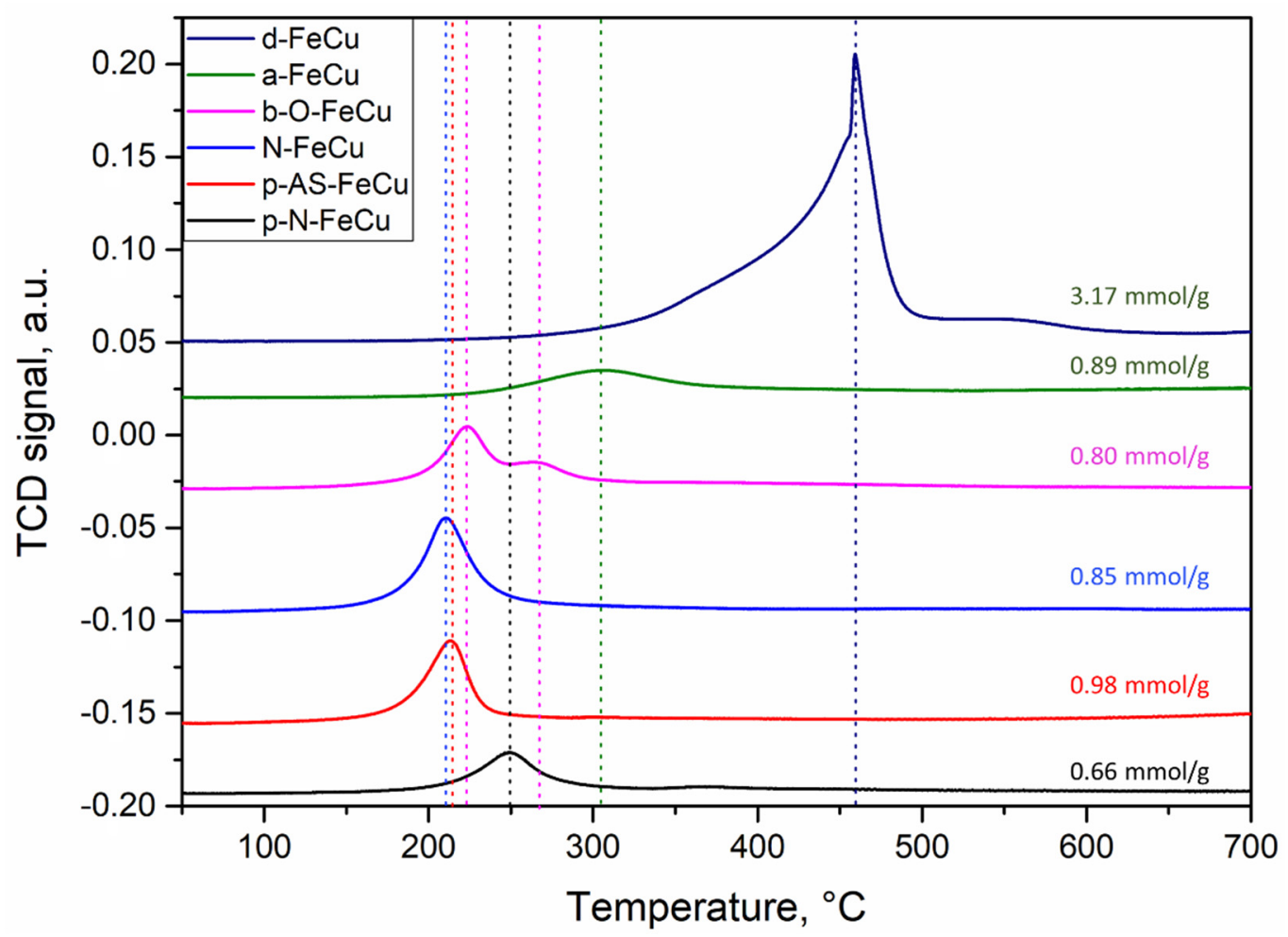

Figure 9. $\mathrm{H}_{2}$-TPR profiles of prepared catalysts with presented experimental consumptions of $\mathrm{H}_{2}$ in $\mathrm{mmol} / \mathrm{g}$.

\subsubsection{Transmission Electron Microscopy (TEM)}

TEM and HAADF-STEM (High-angle annular dark-field scanning transmission electron microscopy) micrographs of catalytically active samples "N-FeCu", "p-AS-FeCu", "p-N-FeCu" and "b-O-FeCu" are shown in Figures 10a-d and 10e-h, respectively. Besides mesoporous $\mathrm{Al}_{2} \mathrm{O}_{3}$ based substrate phase, nanosized copper oxide particles are detected. The addition of $\mathrm{Cu}^{2+}$ cations on the samples leads to the formation of 5-20 nm sized $\mathrm{CuO}$ nanoparticles (Figure 10e-h). The amount and size of this phase is the lowest in sample "N-FeCu". 


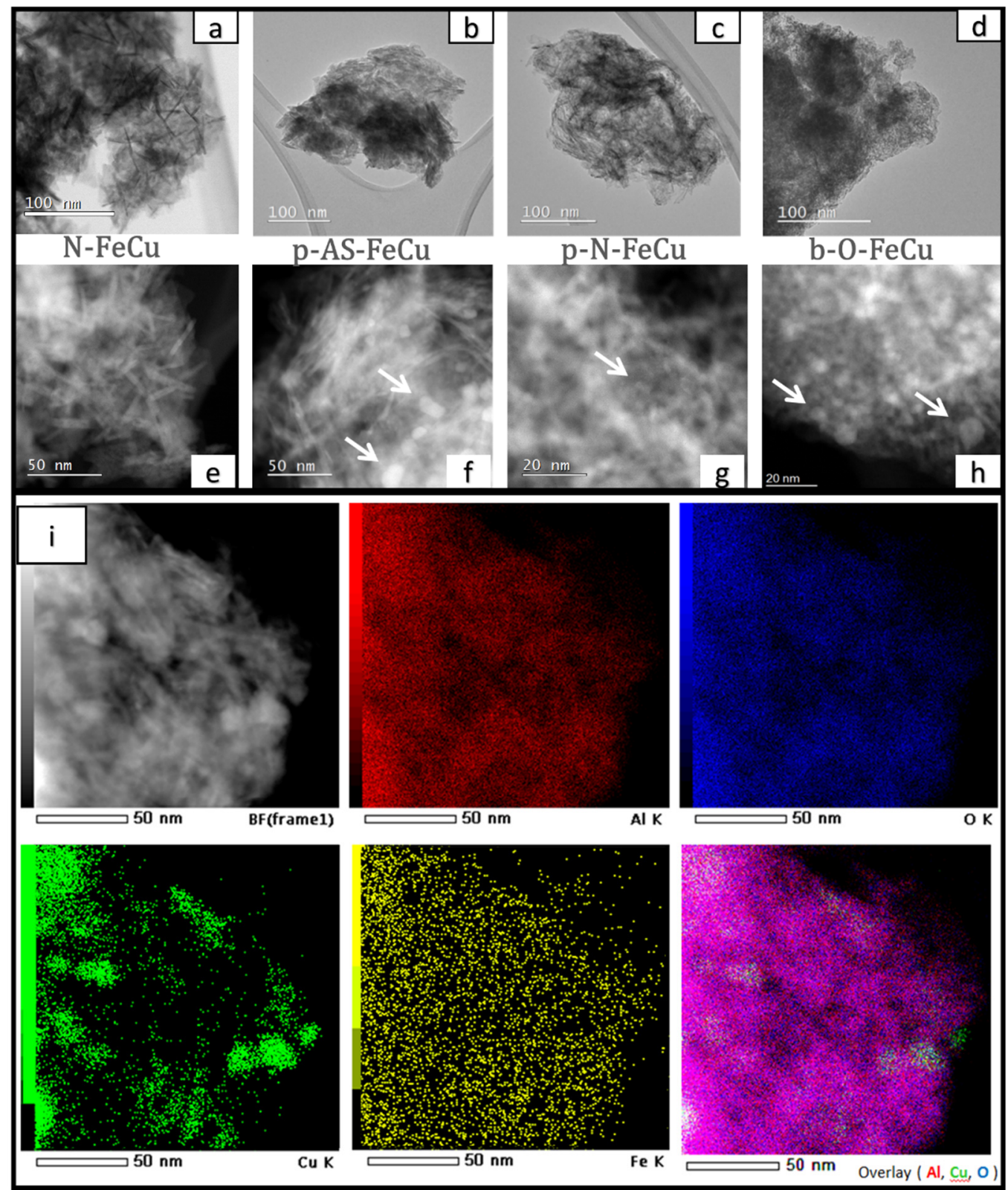

Figure 10. (a-d) TEM micrographs of samples "N-FeCu”, "p-AS-FeCu”, "p-N-FeCu” and "b-O$\mathrm{FeCu}^{\prime}$, respectively; (e-h) HAADF-STEM micrographs of samples showing individual CuO particles. In sample "p-AS-FeCu" and "b-O-FeCu" up to $20 \mathrm{~nm}$ sized particles were detected, while in samples "p-N-FeCu" and "N-FeCu" $\mathrm{CuO}$ particles are smaller and in lower concentration (in all cases indicated with white arrows). (i) EDXS mapping of sample "p-AS-FeCu" where $\mathrm{CuO}$ nanoparticles are clearly visible. Iron and copper are uniformly distributed on $\mathrm{Al}_{2} \mathrm{O}_{3}$ substrate.

TEM micrographs of "N-500", "N-Fe-500", "N-Cu”, and "N-FeCu" are shown in Figure 11a-d, respectively. Sample "N-500" (Figure 11a) is consisting of pure alumina in the form of few nm thick and up to $50 \mathrm{~nm}$ wide sheets or rolled sheets (tubes). Sample "N-Fe-500" (Figure 11b) has uniformly distributed Fe in the basic alumina matrix. In some cases the iron oxide nanoparticles can be observed. For sample "N-Cu", Figure 11(c1) shows detected $\mathrm{CuO}$ particles visible on HAADF and EDXS mapping (marked in red). This is not the case in the site of interest shown in Figure 11(c2). This could indicate that the presence of iron favors an equal and uniform distribution of copper oxide on the surface, as this sample was prepared without the presence of iron. The $\mathrm{CuO}$ particles are also very 
different in size (Figure 11(c3)) ranging from 7 to $75 \mathrm{~nm}$ in size, indicating that the presence of iron contributes also to a more equal size distribution of copper oxide nanoparticles.

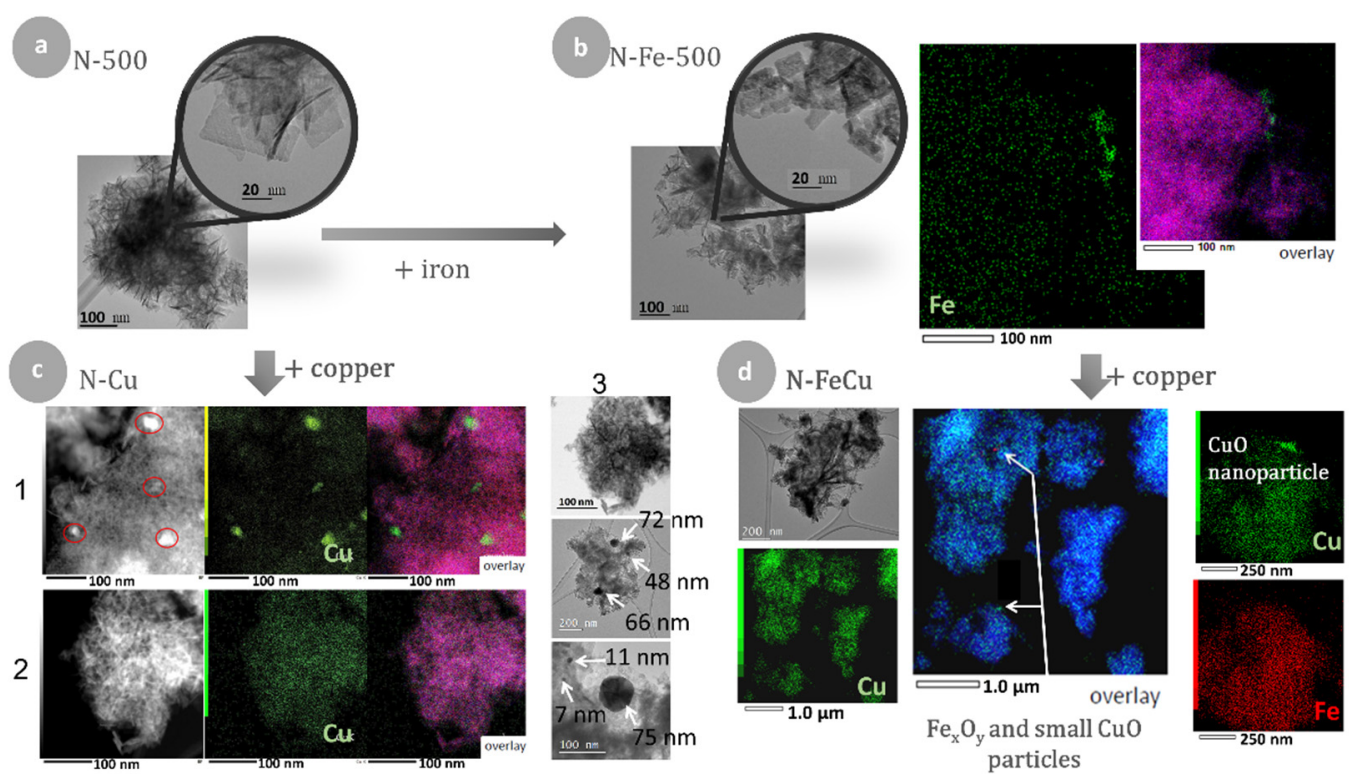

Figure 11. (a) N-500: BF-STEM image of platelet particles; (b) N-Fe-500: BF-STEM image of iron containing particles with EDXS mapping of iron and overlay micrograph. (c) HAADF and BF STEM images with EDXS mappings of catalyst sample N-Cu without iron presence: 1-area with visible copper oxide particles; 2-area without visible copper oxide particles; 3-located copper oxide particles of different sizes. (d) TEM image and EDXS mappings of N-FeCu sample where very rare small nanoparticles of $\mathrm{Fe}_{\mathrm{x}} \mathrm{O}_{\mathrm{y}}$ and $\mathrm{CuO}$ are visible (indicated with white arrows in overlay mapping).

Sample "N-FeCu" (Figure 11d) has an equal iron distribution through the whole surface (deriving from the iron containing sample "N-Fe-500"). Small copper oxide nanoparticles are detected and the presence of $\mathrm{Fe}_{\mathrm{x}} \mathrm{O}_{\mathrm{y}}$ species is observed in those areas.

Sample "d-FeCu" has an alumina matrix consisting of needle-like particles (Figure 12a,c) and is quite inhomogeneous regarding the $\mathrm{Fe}$ and $\mathrm{Cu}$ distribution on the support. Up to $100 \mathrm{~nm}$ large $\mathrm{CuO}$ nanoparticles are found to be present in many areas. Samples with the lowest catalytic activity have also been investigated by means of TEM analysis. Sample with amorphous structure, "a-FeCu", has a different alumina matrix (Figure 12b,d) consisting of roundly shaped particles with $\mathrm{Fe}$ and $\mathrm{Cu}$ that are uniformly distributed inside the matrix and no defined oxide nanoparticles are present in this material.

\subsection{Catalytic Properties of the Catalysts}

The structure stability of the catalyst was analyzed before the catalytic tests in a temperature-programed regime with an XRD in repeated heating and cooling cycles. The structure of the catalyst remained intact according to XRD (Supplementary Materials, Figure S6). Prior to the synthesis and testing of all the catalysts, sample "N-500" was synthesized also without iron and impregnated with copper (II) in order to determine the impact of copper presence on the catalytic oxidation of toluene as a model compound and the coexistence of $\mathrm{Cu}$ and Fe species on alumina support. Figure 13 presents the catalytic activity of samples "N-Fe-500", "N-Cu" and "N-FeCu" with their textural properties: specific surface area $\mathrm{S}_{\mathrm{BET}}$, pore volume $\mathrm{V}_{\mathrm{p}}$ and acid sites concentration. All samples have similar pore volume and specific surface area (Table 1 ), the only difference being the sample "N-Fe-500", which has slightly higher $\mathrm{V}_{\mathrm{p}}$ and $\mathrm{S}_{\mathrm{BET}}$ due to the fact that it is not an impregnated sample where surface area and pore volume decrease occurs. The sample without copper species did not reach even $50 \%$ of conversion of toluene at the highest utilized reaction temperature. The other two samples, "N-Cu" and "N-FeCu", performed better proving that copper is the active component for this reaction. The presence of 
iron in the sample and possible causing of a synergistic effect was visible above $420{ }^{\circ} \mathrm{C}$, when the conversion of the $\mathrm{Cu}$ and Fe combined alumina catalyst exhibited up to $10 \%$ better conversion. At temperatures below $360{ }^{\circ} \mathrm{C}$ the presence of iron seemed to have a negative effect on the oxidation reaction of toluene as the activity of " $\mathrm{N}-\mathrm{Cu}$ " catalyst was higher. Acid site concentration of the support has been improved significantly with copper addition, suggesting that the presence of copper species causes vacancies in the structure and therefore making new acid sites. Another interesting observation was found, namely iron influenced a decrease of the number of acid sites, suggesting that it could be incorporated into the alumina structure compensating the Lewis acidity of alumina, i.e., coordinately unsaturated $\mathrm{Al}^{3+}$ ions. Acid site concentration was increased by two fold in coexistence of copper and iron species, relative to that without $\mathrm{Cu}$. When iron was not present in the sample, this increase was only $29 \%$, relative to alumina support. This could suggest a beneficial interaction between iron and copper leading to more structure defects and causing surface acidity, which is one of the major properties of a catalytic materials for this type of a reaction [50].

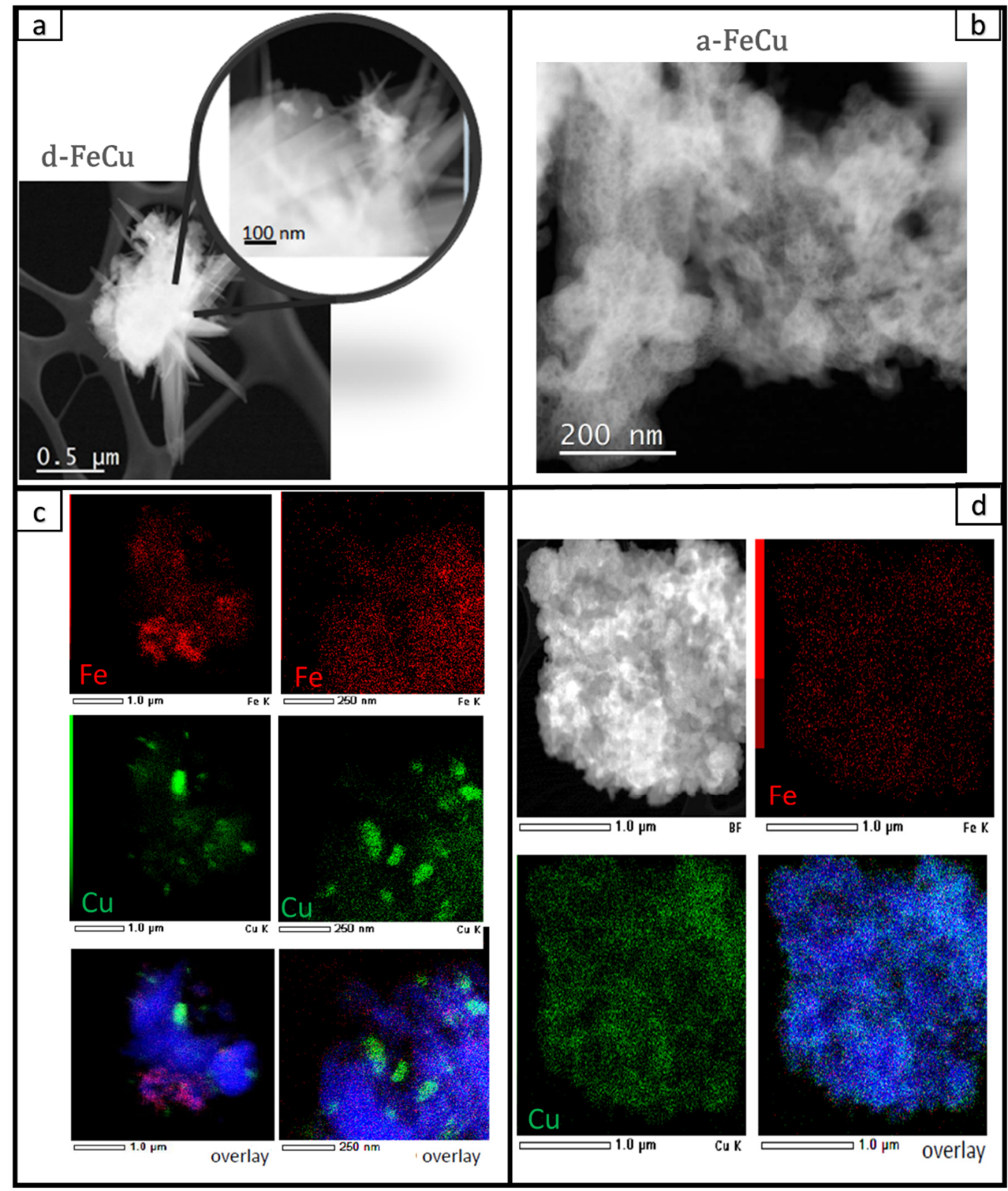

Figure 12. TEM micrographs with elemental mappings of samples "d-FeCu" $(\mathbf{a}, \mathbf{c})$ and "a-FeCu" $(\mathbf{b}, \mathbf{d})$. 


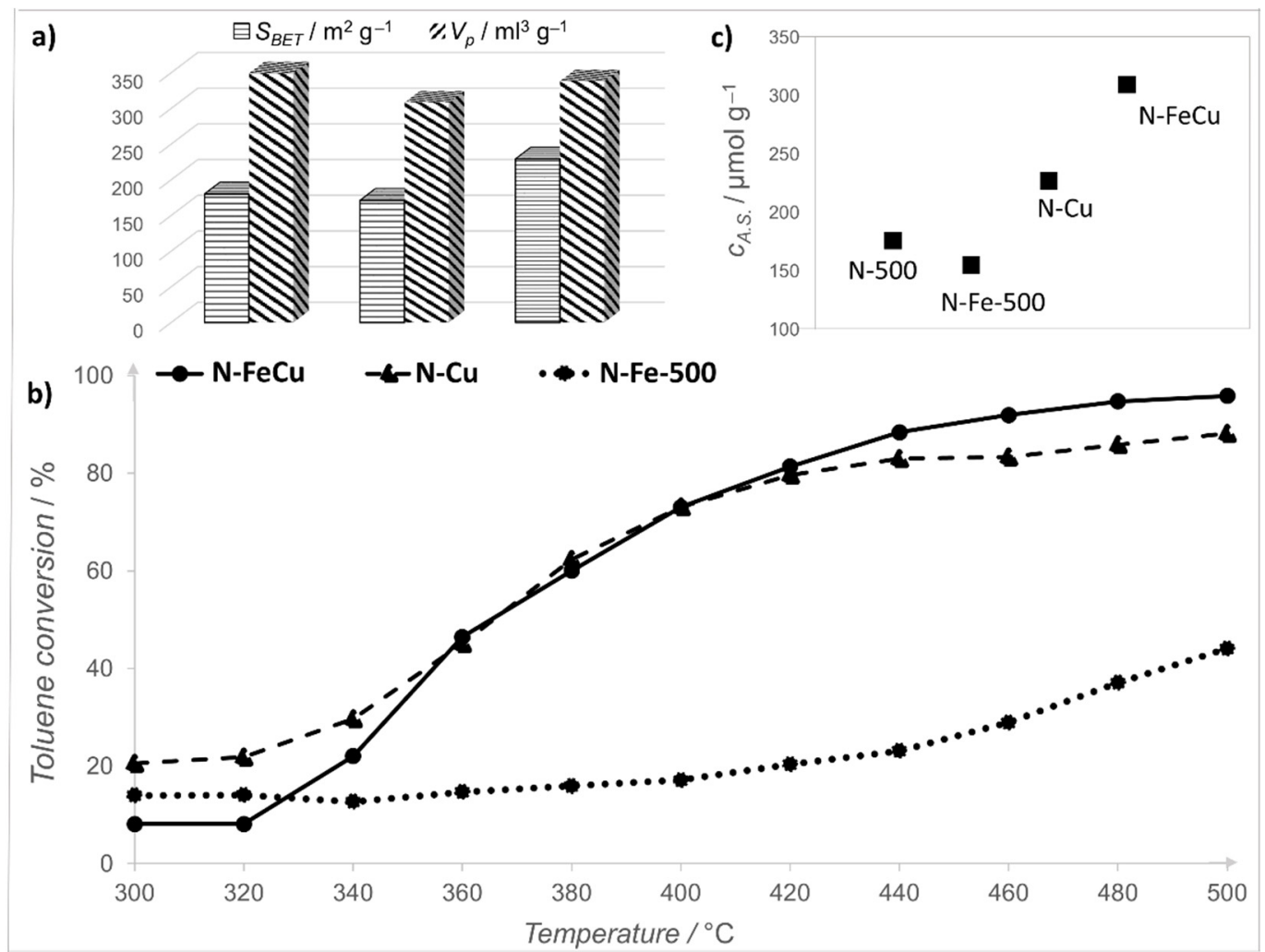

Figure 13. Textural characteristics $S_{B E T}$ and $V_{p}(\mathbf{a})$, catalytic performance $(\mathbf{b})$ and presented concentration of acid sites $c_{A}$.S. (c) of samples $» \mathrm{~N}-\mathrm{Fe} «$, N-Cu« and $» \mathrm{~N}-\mathrm{FeCu}$. WHSV (weight hourly space velocity) $=1.2 \mathrm{~h}^{-1}$.

In all tests, only carbon dioxide and water were the products of toluene oxidation reaction. The studies were performed in a temperature-programed regime to determine the activity of the samples. Results show (Table 2 and Figure 14) that the samples "d$\mathrm{FeCu}$ " and "a-FeCu" performed poorly in this reaction, probably because catalysis is a surface reaction and those two samples exhibited the lowest specific surface area of 26 and $45 \mathrm{~m}^{2} / \mathrm{g}$, respectively. The sample "a-FeCu" had a quite promising starting conversion of toluene $\left(24 \%\right.$ at $\left.300{ }^{\circ} \mathrm{C}\right)$, which could be explained with adsorption of toluene on the alumina surface, or the activity of the catalyst when almost all active sites are occupied and even higher temperatures do not contribute to significant conversion increase due to the mentioned low specific surface area. Besides low specific surface area, this sample is also amorphous. This was not the case for the sample "d-FeCu", where only $30 \%$ conversion was reached at maximum temperature. Besides low specific surface area, this sample had also the most peculiar morphology consisting of approximately $10 \mu \mathrm{m}$ long needles, which exhibited almost no interparticle porosity.

Samples "p-AS-FeCu", "p-N-FeCu", "N-FeCe" and "b-O-FeCu" originating from bayerite and pseudoboehmite precursors, all achieved above $90 \%$ conversion at maximum temperature (Figure 14). The differences in activity between those catalysts were most profound at starting temperature and in the temperature range from 350 to $420^{\circ} \mathrm{C}$. Samples prepared from pseudoboehmite precursors, such as "p-AS-FeCu" and "p-N-FeCu", showed higher $(5 \%$ to $15 \%)$ starting conversions at $300{ }^{\circ} \mathrm{C}$ in comparison to catalysts with bayerite originated supports. This trend was observed until $380^{\circ} \mathrm{C}$. After $380^{\circ} \mathrm{C}$ the conversion of the sample "b-O-FeCu" increased. The reason for high starting conversions of samples "p-AS-FeCu" and "p-N-FeCu" could be in significantly higher pore volume in comparison to samples "N-FeCu" and "b-O-FeCu". 


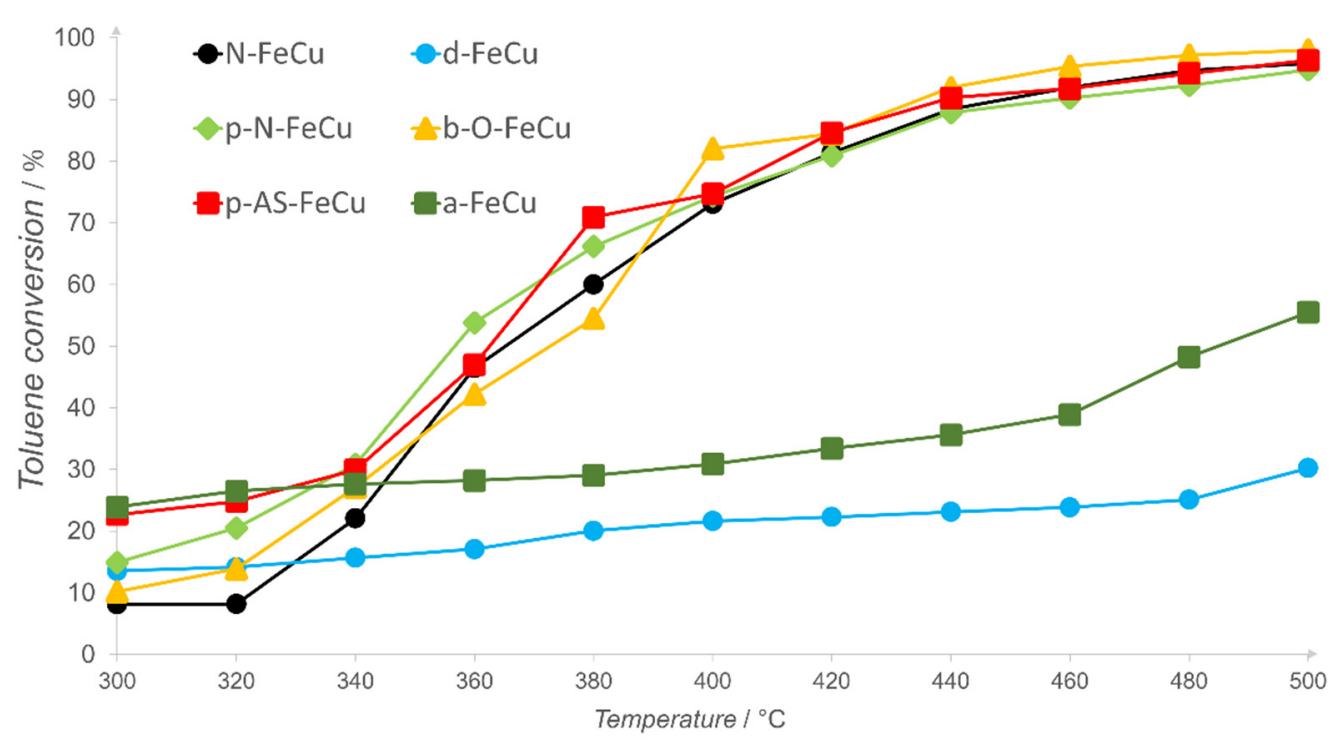

Figure 14. Catalytic performance of $\mathrm{Cu}$ - and Fe-containing phases on different alumina supports. WHSV $=1.2 \mathrm{~h}^{-1}$.

Catalyst "p-AS-FeCu" was chosen for stability and reusability determination (Figure 15). During the time on stream (TOS) the fresh catalyst remained stable, where the conversion of toluene was between $42 \%$ and $50 \%$. After first use, the activity dropped and the toluene conversion was 37\% at the start and $32 \%$ at the end of the test. The second use of the catalyst indicated a slight decrease in activity (34-30\%) but in the similar conversion range as in the previous stage. This could suggest that the changes of the catalyst occur after first cycle and that the catalyst remains almost unchanged after additional cycles of use.

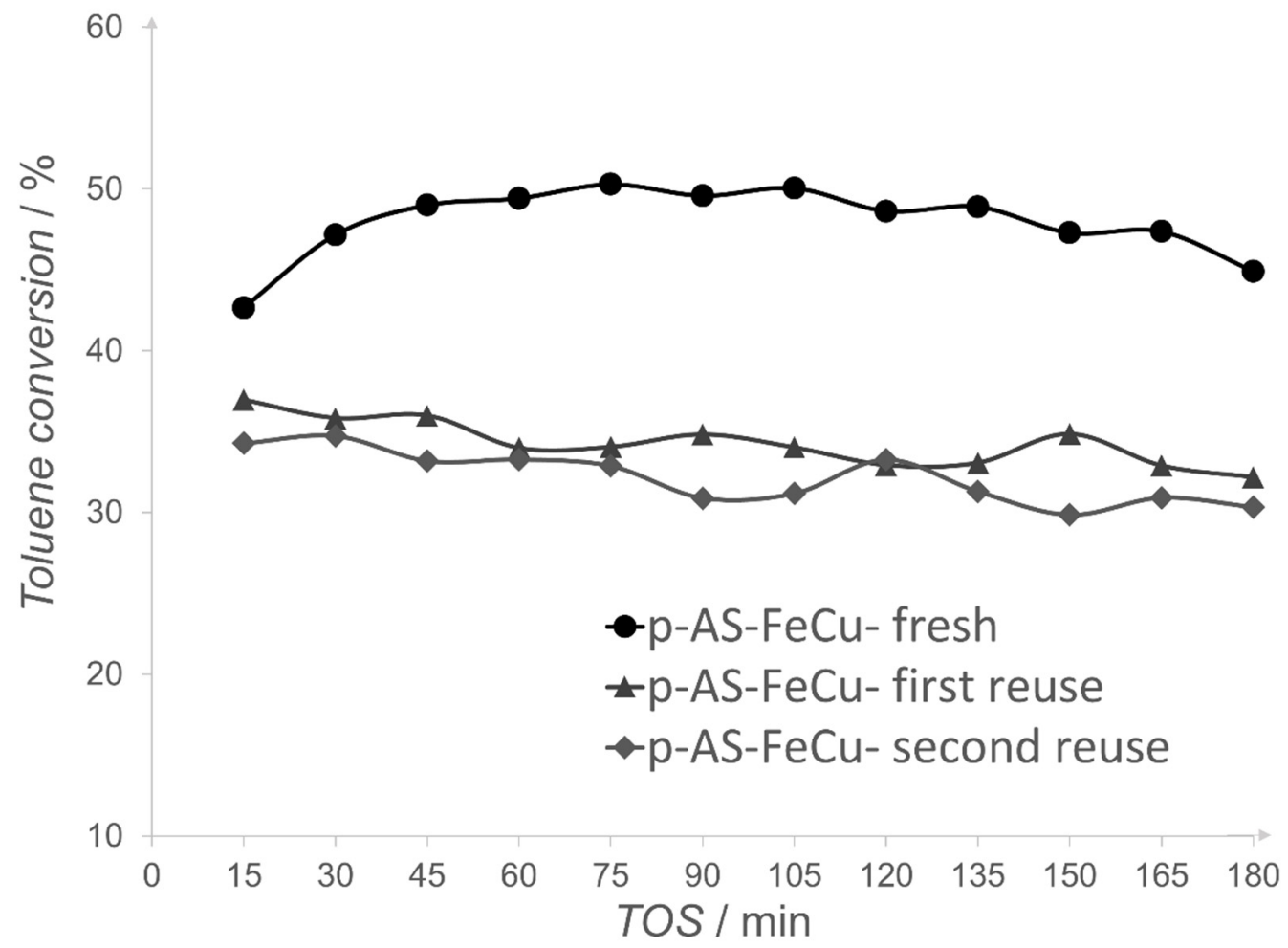

Figure 15. Time on stream (TOS) for catalyst "p-AS-FeCu", with two reuse cycles. WHSV $=1.2 \mathrm{~h}^{-1}, \mathrm{~T}=380^{\circ} \mathrm{C}$. 


\section{Discussion}

In the case of the bayerite derived catalyst support " $\mathrm{N}$ ", the samples were prepared with and without the iron presence in order to observe its influence on the catalyst structure and the activity for the studied oxidation reaction. Alumina precursor structure of bayerite exhibited specific surface area of $230 \mathrm{~m}^{2} / \mathrm{g}$ after thermal treatment at $500{ }^{\circ} \mathrm{C}$. After the impregnation with copper, the specific surface area decreased to $171 \mathrm{~m}^{2} / \mathrm{g}$ and $180 \mathrm{~m}^{2} / \mathrm{g}$ in "N-Cu" and "N-FeCu" samples, respectively. The pore volume remained at similar values around $0.3 \mathrm{~cm}^{3} / \mathrm{g}$, which indicate that the copper species are not causing steric obstacles with blocking smaller pores although they are occupying the alumina support surface. The addition of iron during the synthesis procedure leads to the decrease of acid site concentration, which could be connected with iron-containing species occupying the vacancies in the alumina structure (coordinately unsaturated $\mathrm{Al}^{3+}$ ) and stabilizing them. When copper is introduced, the concentration of acid sites significantly increases from 0.15 to $0.30 \mathrm{mmol}$ per gram in case of iron-containing samples. When both metals are present as in the case of sample "N-FeCu", the concentration of acid sites is around $50 \%$ higher in comparison to the "N-Cu" sample without iron. This corresponds to higher conversion of toluene obtained with the bimetal catalysts and suggests a synergistic effect of the two metals. The bimetal catalysts displayed also more homogeneous copper distribution with presence of copper oxide nanoparticles, which are smaller and have a more narrow size distribution, which was also indicated by $\mathrm{H}_{2}$-TPR. In the case of sample prepared without iron, " $\mathrm{N}-\mathrm{Cu}$ ", $\mathrm{CuO}$ nanoparticles were unevenly distributed and their size distribution was broader, ranging from 7 to $72 \mathrm{~nm}$, indicating that the presence of iron in the sample leads to formation of more uniform and smaller copper oxide nanoparticles as well as more equal distribution through the whole surface of the alumina support of suitable characteristics, which has consequently the favorable effect on the catalyst performance. Another bayerite derived catalyst "b-O-FeCu", displayed the lowest catalytic activity at lower temperatures. Its activity significantly improved above $400{ }^{\circ} \mathrm{C}(84 \%$ toluene conversion), which is in agreement with its bimodal reduction profile, with a second peak in higher temperature region. Although it had a higher specific surface area in comparison to "N-FeCu" catalyst, the pore volume was lower for about one quarter in comparison to the latter. TEM showed similar copper and iron distribution, indicating that the preparation difference between the two bayerite originating catalysts does not affect the structure and performance significantly.

Two catalytically active samples deriving from alumina precursors with ordered structures of pseudoboehmite ( $\mathrm{p}-\mathrm{AS}-\mathrm{FeCu}, \mathrm{p}-\mathrm{N}-\mathrm{FeCu}$ ), loaded with copper and iron species, were prepared and studied. Pseudoboehmite derived samples were much more active at lower temperatures as they reached $30 \%$ conversion of toluene at $340{ }^{\circ} \mathrm{C}$ (Table 2). Sample "p-N-FeCu" stood out in terms of surface characteristics as it possessed the highest specific surface area of $286 \mathrm{~m}^{2} / \mathrm{g}$ and by far largest pore volume of $1.11 \mathrm{~cm}^{3} / \mathrm{g}$ (Table 2). Surprisingly, it did not outperform other catalysts, which means that the surface characteristics are important, but not performance determining. The latter was also confirmed with $\mathrm{H}_{2}$-TPR, where this sample was reduced at the highest temperatures in comparison to other catalytically active materials. Interesting observation was found in case of the other pseudoboehmite derived sample, "p-AS-FeCu", which had the lowest $\mathrm{Cu} / \mathrm{Al}$ molar ratio of all the catalysts, but nonetheless outperformed some of the catalysts such as "N-FeCu", " $\mathrm{p}-\mathrm{N}-\mathrm{FeCu}$ " or "a-FeCu", and even displayed most promising activity rates at around $380^{\circ} \mathrm{C}$.

From morphological perspective, samples are very different (Figure 5). The influence of morphology on the catalyst performance was studied by Lee et al. [51], who investigated dehydration of ethanol. They prepared $\mathrm{Al}_{2} \mathrm{O}_{3}$ samples of different morphologies, crystalline phases and studied an influence of additives on acid-base properties of alumina. Their conclusion was that the crystalline phases and additives affected the dehydration rate more drastically than morphology. More in depth study of the morphology and distribution of iron and copper was studied in the present work with HRTEM/STEM and EDXS. 
All samples, except sample "d-FeCu" with a needle-like morphology, had a uniform iron distribution through the whole surface of the catalyst. Copper was evenly distributed in samples "N-FeCu", "p-N-FeCu", "b-O-FeCu", "p-AS-FeCu" and "a-FeCu", and in all cases except of the latter, $\mathrm{CuO}$ nanoparticles were observed.

\section{Materials and Methods}

Catalyst with $\mathrm{Cu}$ and Fe were prepared on different alumina supports. Various synthesis techniques found in literature were studied and tested [27,33,34]. With respect to the proposed focus of the study, only those techniques that involve inorganic aluminum precursors were chosen, as they enable more feasible production approach in comparison to some organic precursors (aluminum butoxide, aluminum isopropoxide) and related synthesis procedures often found in the literature [25,35]. Together with a more accessible production procedure to manufacture aluminum oxide on large scale, environmental aspects were taken into consideration, while additional treatments of byproducts and organic solvents are often required when organic raw materials are used. As stated in various studies, most synthesis procedures of aluminum oxide involve a transient pseudoboehmite phase or even don't form structured alumina supports $[19,36]$. Thus, corresponding aluminum hydroxide is formed and subsequently dehydrated to aluminum oxide. As it is known, the surface and chemical properties of aluminum oxides strongly depend of the properties of their hydroxide precursors $[23,26]$ and dehydration temperature $[22,25,37]$. In this study, different materials such as pseudoboehmite $(\mathrm{AlO}[\mathrm{OH}])$, bayerite $\left(\alpha-\mathrm{Al}[\mathrm{OH}]_{3}\right)$ and sodium dawsonite $\left(\mathrm{NaAlCO}_{3}[\mathrm{OH}]_{2}\right)$ were prepared to investigate the impact of alumina structure, morphology and surface properties in a $\mathrm{Cu}-\mathrm{Fe}$ bimetal catalyst used for gas-phase catalytic oxidation of toluene.

\subsection{Catalyst Synthesis}

\subsubsection{Materials}

Sodium aluminate solution with a molar ratio $\mathrm{Na}_{2} \mathrm{O} / \mathrm{Al}_{2} \mathrm{O}_{3}$ of 1.78 , density $\rho=1.34 \mathrm{~g} / \mathrm{l}$, $\mathrm{c}\left(\mathrm{Na}_{2} \mathrm{O}\right)=165.9 \mathrm{~g} / \mathrm{l}$ and $\mathrm{c}\left(\mathrm{Al}_{2} \mathrm{O}_{3}\right)=153.5 \mathrm{~g} / 1$ was acquired from Silkem, Slovenia, nitric acid, $51 \%$ and iron (III) chloride hexahydrate $(99.4 \%)$ from VWR, Radnor, PA, USA, ammonium acetate, carbon dioxide of $4 \mathrm{~N}$ purity from Messer, Bad Soden, Germany, aluminum chloride hexahydrate, 99\%, from Alfa Aesar, Haverhill, MA, USA and copper (II) nitrate trihydrate, EMSURE quality, from Merck, Kenilworth, NJ, USA. Sodium dodecylbenzensulfonic acid (NaDBS) was also provided by Silkem, Slovenia.

\subsubsection{Synthesis}

One sodium dawsonite $\left(\mathrm{NaAlCO}_{3}[\mathrm{OH}]_{\mathrm{W}}\right)$, one amorphous alumina, two different bayerites $\left(\alpha-\mathrm{Al}[\mathrm{OH}]_{3}\right)$ and two pseudoboehmites $(\mathrm{AlO}[\mathrm{OH}])$ based $\mathrm{Cu}-\mathrm{Fe}$ catalysts were prepared and studied.

In all cases, iron was introduced during the synthesis of the alumina precursor. Further, all iron containing alumina precursors were dried at $105^{\circ} \mathrm{C}$ for $24 \mathrm{~h}$ and then calcined at $500{ }^{\circ} \mathrm{C}$ for $2 \mathrm{~h}$, with a heating ramp of $100^{\circ} \mathrm{C} / \mathrm{h}$. Copper was loaded with an impregnation method on calcined iron-containing alumina precursors. The content of iron in ironcontaining alumina precursors was adjusted to theoretical value of $0.8 \mathrm{wt} \%$ of $\mathrm{Fe}_{2} \mathrm{O}_{3}$. The desired copper oxide amount in the iron-containing alumina was $6 \mathrm{wt} \%$. The samples were denoted according to their preparation procedure and structure. The nomenclature of the samples is shown in Figure 16. The descriptions of the synthesis procedures for precursors are explained in more detail in the Supplementary Materials, Figure S1. 


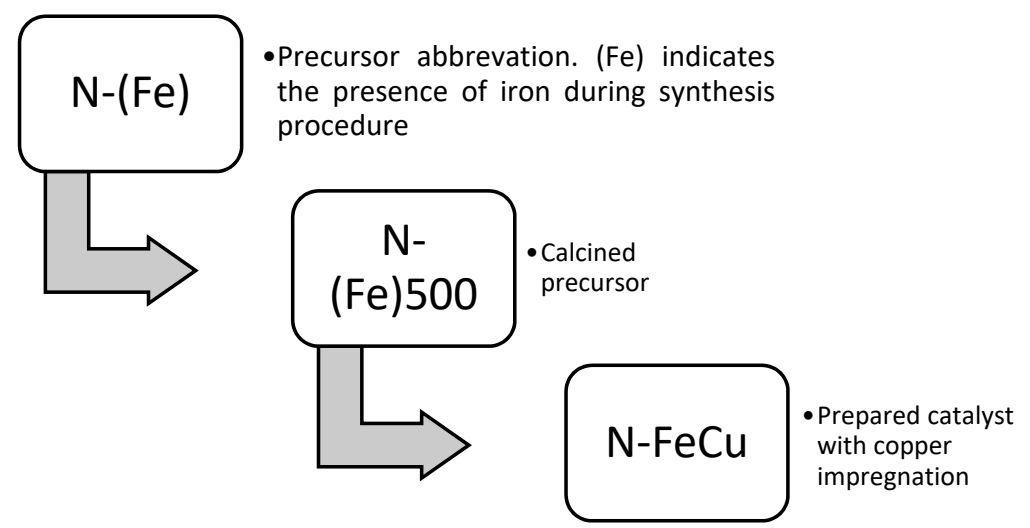

Figure 16. Sample nomenclature.

Similar metal compositions were achieved in all samples (Table 3), which was confirmed by XRF. The desired theoretical value of $\mathrm{Fe} / \mathrm{Al}$ molar ratio of 0.005 and copper oxide content of $6 \mathrm{wt} \%$ was satisfyingly reached. The discrepancies can be to a certain degree assigned also to measurement error, especially in the case of Fe content where the quantities are lower.

Table 3. Elemental analysis and presented $\mathrm{Fe} / \mathrm{Al}$ and $\mathrm{Cu} / \mathrm{Al}$ molar ratio of bayerite $\left(\alpha-\mathrm{Al}[\mathrm{OH}]_{3}\right)$, pseudoboehmite $(\mathrm{AlO}[\mathrm{OH}])$, amorphous alumina and sodium dawsonite $\left(\mathrm{NaAlCO}_{3}[\mathrm{OH}]_{\mathrm{W}}\right)$ derived catalysts.

\begin{tabular}{|c|c|c|c|c|c|c|}
\hline $\begin{array}{c}\text { Sample } \\
\text { Abbreviation }\end{array}$ & $\begin{array}{c}\text { Preparation } \\
\text { Difference }\end{array}$ & $\begin{array}{l}\text { Precursor } \\
\text { Structure }\end{array}$ & $\mathrm{CuO}(w \mathrm{t} \%)$ & $\mathrm{Fe}_{2} \mathrm{O}_{3}(w t \%)$ & $\begin{array}{c}\text { Fe/Al } \\
\text { Molar Ratio }\end{array}$ & $\begin{array}{c}\text { Cu/Al } \\
\text { Molar Ratio }\end{array}$ \\
\hline $\mathrm{a}-\mathrm{FeCu}$ & / & Amorphous & 7.32 & 0.539 & 0.004 & 0.056 \\
\hline $\mathrm{d}-\mathrm{FeCu}$ & / & Dawsonite & 7.67 & 0.740 & 0.007 & 0.069 \\
\hline $\mathrm{N}-\mathrm{FeCu}$ & Nitric acid & Bayerite & 9.17 & 0.558 & 0.004 & 0.066 \\
\hline $\mathrm{p}-\mathrm{N}-\mathrm{FeCu}$ & $\begin{array}{c}\text { Nitric acid, } \\
\text { without HT }{ }^{1}\end{array}$ & Pseudoboehmite & 8.00 & 1.010 & 0.008 & 0.063 \\
\hline p-AS-FeCu & Al salts, $\mathrm{HT}^{1}$ & Pseudoboehmite & 6.42 & 0.551 & 0.004 & 0.045 \\
\hline $\mathrm{b}-\mathrm{O}-\mathrm{FeCu}$ & Organic acid & Bayerite & 6.81 & 0.854 & 0.004 & 0.056 \\
\hline
\end{tabular}

${ }^{1} \mathrm{HT}=$ hydrothermal treatment.

Two additional samples were studied for the purpose of proof of concept that bimetal $\mathrm{Cu}-\mathrm{Fe}$ catalysts could be used for catalytic oxidation of toluene and that the combination of the two metal species has a synergistic effect (Table 4). Sample N-Fe-500 was prepared without the impregnation step with copper (II) nitrate trihydrate and the sample N-Cu was prepared without the introduction of iron (III) chloride hexahydrate during the synthesis procedure. The synthesis of the alumina support of two samples, N-Fe and $\mathrm{N}-\mathrm{Cu}$, was done with the same procedure as in the case of sample N-FeCu.

Table 4. Samples with iron (N-Fe-500), copper (N-Cu) and both metals (N-FeCu); chemical composition and $\mathrm{Cu} / \mathrm{Al}$ and $\mathrm{Fe} / \mathrm{Al}$ molar ratio.

\begin{tabular}{cccccc}
\hline $\begin{array}{c}\text { Sample } \\
\text { Abbreviation }\end{array}$ & $\begin{array}{c}\text { Precursor } \\
\text { Structure }\end{array}$ & $\begin{array}{c}\mathbf{C u O} \\
\mathbf{( w t \% )}\end{array}$ & $\begin{array}{c}\mathbf{F e}_{2} \mathbf{O}_{3} \\
\mathbf{( w t \% )}\end{array}$ & $\begin{array}{c}\mathbf{F e} / \mathrm{Al} \\
\text { Molar Ratio }\end{array}$ & $\begin{array}{c}\mathbf{C u} / \mathrm{Al} \\
\text { Molar Ratio }\end{array}$ \\
\hline $\mathrm{N}-\mathrm{FeCu}$ & Bayerite & 9.17 & 0.556 & 0.004 & 0.066 \\
$\mathrm{~N}-\mathrm{Cu}$ & Bayerite & 9.56 & 0.056 & 0.000 & 0.069 \\
$\mathrm{~N}-\mathrm{Fe}-500$ & Bayerite & 0.01 & 0.512 & 0.003 & 0.000 \\
$\mathrm{~N}-500$ & Bayerite & 0.00 & 0.000 & 0.000 & 0.000 \\
\hline
\end{tabular}

\subsection{Catalyst Characterization}

X-ray diffraction was performed on PANalytical X'pert PRO MPD, Malvern PANalytical, Worchestershire, UK, with CuK $\alpha 1$ radiation of $\lambda=1.5406 \AA$. Measurements were 
performed at ambient conditions with a step of $0.034^{\circ} 2 \theta$ between 5 and $80^{\circ} 2 \theta$. XRD patterns were analyzed by using X'pert software V 2.2.3, from PANalytica, Malvern, UK, 2007.

Elemental analysis was performed on a AXS S8-TIGER XRF model from BRUKER, Billerica, MA, USA, with $1 \mathrm{~kW}$ rhodium tube and PET, XS-55, XS-Ge-C and LiF200 analyzer crystals using vacuum. The detectors used were flow and scintillation counters typical for this model. The samples were prepared in a platinum dish with lithium tetraborate flux (type LT100 Granular) addition in ratio 1:8 (sample: flux) and melted with a Soahchim Phoenix R sample preparation unit from Xrf Sxientific, Australia, with the flame temperature at $1320-1350{ }^{\circ} \mathrm{C}$ for $800 \mathrm{~s}$. The results were collected and analyzed using Spectra plus Measurement and Launcher V 2.2.47 software from BRUKER, Billerica, MA, USA, 2015. Two different calculation methods were used to avoid any miscalculations, especially due to the low amount of iron in the samples. Samples were dried and calcined prior to analysis. The loss of ignition was identified as water loss and accounted in the total mass of the sample for correct data analysis.

Scanning electron microscopy (SEM) was performed on Zeiss Supra TM 35 VP model from Carl Zeiss AG, Oberkochen, Germany and was used to determine the morphology of the samples.

Physisorption was conducted with volumetric adsorption analyzer Tristar 3000 (Micromeritics, Communications Drive Norcross, GA, USA), using nitrogen as the adsorbing gas. Sample was degassed at $200{ }^{\circ} \mathrm{C}$ for $12 \mathrm{~h}$. The BET [35] specific surface area was determined from adsorption data in the relative pressure range from 0.05 to 0.30 . The total pore volume was estimated based on the amount of adsorbed nitrogen at the relative pressure of 0.98 . Due to different types of isotherms, the total pore volume of type III isotherm serves only as estimation. Pore size distributions were calculated based on the $\mathrm{BJH}$ logarithm [35] for adsorption. The diameters of pores were taken at maxima of the pore size distributions.

Analysis for determination of acid sites was performed on Perkin Elmer (Waltham, MA, USA) TGA Pyris 1 thermogravimetric analyzer (TGA), coupled with thermal analysis gas station (TAGS) and using pyridine as a model adsorption molecule. Sample was pre-treated in air stream $(50 \mathrm{~mL} / \mathrm{min})$, heated to $500^{\circ} \mathrm{C}$ with a heating ramp $10^{\circ} \mathrm{C} / \mathrm{min}$, and held at this temperature for $15 \mathrm{~min}$ to degas the sample. The sample was cooled to $120{ }^{\circ} \mathrm{C}$ with the same ramp of $10{ }^{\circ} \mathrm{C} / \mathrm{min}$ and held at that temperature for $10 \mathrm{~min}$ and the gas was switched from air to nitrogen $(30 \mathrm{~mL} / \mathrm{min})$. After few minutes, pyridine was introduced with flow of nitrogen until the stable conditions were achieved (steady sample weight). Pyridine flow was stopped and the sample remained at $120{ }^{\circ} \mathrm{C}$ for $120 \mathrm{~min}$, to degas the weakly bound pyridine. Afterwards, the sample was heated to $500{ }^{\circ} \mathrm{C}$ with the ramp of $20^{\circ} \mathrm{C} / \mathrm{min}$ and cooled don with the rate of $10^{\circ} \mathrm{C} / \mathrm{min}$. The concentration of acid sites was calculated based on the weight difference of the sample before and after the saturation of pyridine and was presented as total number of moles of pyridine on gram or square meter of the sample. Strength of the pyridine bonding and therefore the strength of acid sites was estimated with a derivative of the temperature programed desorption curve, taking into account that stronger acid sites release pyridine at higher temperatures. Results were displayed as temperature programed desorption curves with peak maxima indicating pyridine desorption temperature.

UV-Vis DRS spectra were recorded on a Perkin Elmer (Waltham, MA, USA) Lambda 35 spectrophotometer equipped with a Praying Mantis accessory. Background was recorded with Spectralon ${ }^{\circledR}$ reference. Samples were scanned in the spectral range between 200 and $900 \mathrm{~nm}$, with slit set to $2 \mathrm{~nm}$ and scanning speed of $240 \mathrm{~nm} / \mathrm{min}$.

FTIR spectroscopy measurements using attenuated total reflectance (ATR) accessory were carried out by using a Perkin Elmer (Waltham, MA, USA) FTIR spectrophotometer using a diamond crystal in a horizontal position. ATR-FTIR spectra were collected in the spectral region from 4000 to $400 \mathrm{~cm}^{-1}$ with a resolution of $2 \mathrm{~cm}^{-1}$.

Solid-state 27Al magic-angle spinning (MAS) NMR spectra were recorded on a $600 \mathrm{MHz}$ Varian NMR system (Varian, Palo Alto, CA, USA), operating at ${ }^{27} \mathrm{Al}$ Larmor 
frequency of $156.19 \mathrm{MHz}$. Sample rotation frequency was $20 \mathrm{kHz}$, repetition delay between consecutive scans was $5 \mathrm{~s}$ and the number of scans was 480 . In all spectra frequency axis in ppm is reported relative to the signal of $\mathrm{Al}$ nuclei within $1 \mathrm{M} \mathrm{Al}\left(\mathrm{NO}_{3}\right)_{3}$ solution.

Reducibility characteristics were determined with the use of Micromeritics AutoChem 2920 II (Micromeritics, Communications Drive Norcross, GA, USA) in a hydrogen reduction in a temperature-programed regime $\left(\mathrm{H}_{2}\right.$-TPR). Approximately $50 \mathrm{mg}$ of sample in a Ushaped quartz reactor was pretreated in stream of $5 \% \mathrm{O} 2 / \mathrm{He}$ at $400{ }^{\circ} \mathrm{C}$. After cooling to $50{ }^{\circ} \mathrm{C}$, argon atmosphere was introduced for $10 \mathrm{~min}$ and afterwards the sample was exposed to $25 \mathrm{~mL} / \mathrm{min}$ of $5 \% \mathrm{H}_{2} /$ Ar mixture during the temperature programed regime to $700{ }^{\circ} \mathrm{C}\left(10^{\circ} / \mathrm{min}\right.$ ramp). Reduction profile was recorded with an integrated TCD detector and a liquid isopropanol/ $\mathrm{LN}_{2}$ cold trap was used to eliminate the water effect to the recorded profile.

Morphology characteristics, the presence of copper nanoparticles, the presence, concentration and distribution of copper and iron and their structural correlation with the alumina support were investigated by high-resolution transmission electron microscopy (HRTEM) and scanning transmission electron microscopy (STEM). The analysis was performed on a Cs probe corrected STEM JEOL ARM 200 CF (Jeol, Akishima, Tokio, Japan) with the cold-FEG cathode. The latter was equipped with a dual-EELS system Quantum ER from Gatan and Centurio EDXS system with $100 \mathrm{~mm}^{2}$ SDD detector. For HRTEM studies a drop of an ethanol diluted sample suspension was placed on a lacey-carbon coated nickel grid and dried at room temperature. Two observation techniques were used in the STEM mode, high-angle annular dark-field (HAADF) imaging and bright-field (BF) imaging.

\subsection{Catalytic Performance}

Catalytic tests were performed in a fixed-bed reactor consisting of a gas inlet, quartz glass tube $15 \mathrm{~mm}$ in diameter, and a gas outlet. The latter was on line connected with a gas chromatography NEXIS GC-2030 ATF apparatus from Shimadzu, Kyoto, Japan, equipped with a FID and TCD detectors. For each test, $50 \mathrm{mg}$ of a sample in catalyst particle size range between 0.2 and $0.8 \mathrm{~mm}$ was combined with glass beads of $1.2 \mathrm{~mm}$ in diameter. The catalyst was pretreated in situ before each test in the following manner: heating to $400{ }^{\circ} \mathrm{C}$ for $1 \mathrm{~h}$ and then cooling down to the lowest test temperature (around $300{ }^{\circ} \mathrm{C}$ ), all in presence of nitrogen. Catalytic activity was studied in a temperature programed regime with an air stream saturated with toluene that was lead through the fixed-bed reactor and then to the GC apparatus. Saturation of toluene was performed with $30 \mathrm{~mL} / \mathrm{min}$ of air passing through the toluene solution at $0{ }^{\circ} \mathrm{C}$. The partial pressure of toluene at that temperature was $0.9 \mathrm{kPa}$. Activity of the samples was tested between 300 and $500{ }^{\circ} \mathrm{C}$ at WHSV (weight hourly space velocity) of $1.2 \mathrm{~h}^{-1}$. Temperature of the fixed-bed was measured with a thermocouple inserted in the quartz housing in the area of the packing. To prevent condensation and toluene wall adsorption after the reaction, the lines were heated. Conversion of toluene at certain temperature, $X_{t}$, was calculated as $X_{t}=\left(\left(c_{0}-c_{t}\right) / c_{0}\right) \cdot 100(\%)$, where $c_{0}$ represents the initial toluene concentration and $c_{t}$ the measured concentration of toluene. $\mathrm{CO}_{2}$ and water were the only products which were detected during the catalytic reaction. The products of partial oxidation (benzaldehyde and benzoic acid) were not detected. The determined carbon mass balance is $98-100 \%$ in all catalytic experiments. The catalytic stability of the samples was tested isothermally at $380{ }^{\circ} \mathrm{C}$.

\section{Conclusions}

Different alumina precursors were prepared using various synthesis methods to study bimetal $\mathrm{Cu}$-Fe catalysts and impact of the support for VOCs total oxidation reaction. Structure, morphology and chemical composition of alumina were studied in correlation with catalytic activity for oxidation of toluene as a model VOC compound. Besides that, the influence of iron presence in $\mathrm{Cu}$-Fe bimetal alumina support was investigated. Iron and copper loadings were similar in all catalysts with target values of $6 \mathrm{wt} \%$ of $\mathrm{CuO}$ and $0.005 \mathrm{Fe} / \mathrm{Al}$ molar ration as shown by XRF. 
The catalytic tests performed in a fixed-bed reactor showed that the two catalysts, "d$\mathrm{FeCu}$ " derived from dawsonite and amorphous alumina "a-FeCu", had the lowest activity for this type of the reaction. Both had the lowest specific surface area and concentration of acid sites among all the tested catalysts. Catalysts " $\mathrm{d}-\mathrm{FeCu}$ " and "a-FeCu" possess four to eleven times less surface area in comparison to the other tested materials, which offers less adsorption sites for the reactant to be adsorbed. An interesting result is that the sample "a-FeCu" contains around two times more acid sites per square meter of surface area, but 1.7- to 3.5-times less with the same mass, in comparison to the other catalysts. This is due to the amorphous structure of this sample consisting of five-coordinated $\mathrm{Al}$ and Lewis acid sites (confirmed with NMR characterization) and the reduction characteristics of the two samples, which display the reduction peak at the highest temperatures amongst all catalysts. This indicates that the reactor loading of these catalysts should be at least two times higher than that of other catalysts in order to achieve similar activities. TEM analysis on these two samples, also showed uneven metal distribution accompanied with larger, above $100 \mathrm{~nm}$, copper oxide particles in the former catalyst, and very homogenous metal distribution, but without any indication of copper oxide particles in the latter. UV-Vis DRS results indicated also the presence of larger $\mathrm{Fe}_{2} \mathrm{O}_{3}$ nanoparticles in both catalysts. A closer look with TEM also revealed very inhomogeneous $\mathrm{CuO}$ distribution in the "d-FeCu" and the lack of copper oxide nanoparticles in the "a-FeCu". The distribution and the presence of uniformly sized $\mathrm{CuO}$ particles were deemed as necessary for good catalytic performance.

On the other hand, iron and copper were homogenously distributed through the whole surface and some smaller sized $(<20 \mathrm{~nm}) \mathrm{CuO}$ nanoparticles were observed in pseudoboehmite "p-AS-FeCu" and "p-N-FeCu" and bayerite support-originating catalysts "b-O-FeCu" and "N-FeCu". The presence of octahedral $\mathrm{Fe}^{3+}$ and $\mathrm{Cu}^{2+}$ in small oligomeric $\mathrm{Fe}_{\mathrm{x}} \mathrm{O}_{\mathrm{y}}$ and $\mathrm{CuO}_{\mathrm{x}}$ clusters and $\mathrm{CuO}$ nanoparticles was determined by UV-Vis DR spectra. It was also noticed that the surface characteristics, such as specific surface area and concentration of acid sites, had an important role in the activity of these catalysts, but were not crucial or their effect diminishes above a certain value. This was observed especially in the case of sample "p-N-FeCu", which had the highest specific surface area, pore volume and concentration of acid sites per gram of catalyst, but did not outperform other catalysts in the studied oxidation reaction. These observations indicated that the catalyst performed better for the studied reaction, when the support had an ordered crystal structure with $\mathrm{AlO}_{4}$ and $\mathrm{AlO}_{6}$ groups with relative abundancies of 0.30 and 0.70 , respectively, a reasonable specific surface area $\left(>100 \mathrm{~m}^{2} / \mathrm{g}\right)$ and when simultaneous presence of $\mathrm{Fe}_{\mathrm{x}} \mathrm{O}_{\mathrm{y}}$ and $\mathrm{CuO}_{\mathrm{x}}$ clusters and below $20 \mathrm{~nm}$ large $\mathrm{CuO}$ nanoparticles were observed on its surface. During the study of iron impact on the performance of $\mathrm{Cu}-\mathrm{Fe}$ bimetal catalysts, slightly improved activity was observed. Broader particle size distribution and less homogeneous distribution of copper oxide nanoparticles was observed in the catalyst prepared without presence of iron. The study showed a beneficial effect of small concentration of iron, introduced during the synthesis procedure of the alumina support precursor, leading to a more homogeneous metal oxides distribution on the support.

Supplementary Materials: The following are available online https:/ / www.mdpi.com/2073-4344/ $11 / 2 / 252 / s 1$.

Author Contributions: Conceptualization and methodology, T.Ž. and N.N.T.; formal analysis, T.Ž., A.R., G.D., H.L. and J.V.; investigation, T.Ž.; writing-original draft preparation, T.Ž., A.R., G.D., H.L. and J.V.; writing-review and editing, A.R., A.P., N.Z.L. and N.N.T.; visualization, T.Ž.; supervision, N.N.T.; project administration, N.N.T.; funding acquisition, A.P. and N.Z.L. All authors have read and agreed to the published version of the manuscript.

Funding: This research was funded by Slovenian Research Agency (research programs P1-0021 and P2-150), Slovenia and the European Regional Development Fund within the Operational Program Science and Education for Smart Growth 2014-2020 under the Project Center of Excellence: National center of mechatronics and clean technologies-BG05M2OP001-1.001-0008, Bulgaria.

Institutional Review Board Statement: Not applicable. 
Informed Consent Statement: Not applicable.

Data Availability Statement: The data presented in this study are available on request from the corresponding author.

Acknowledgments: The authors would like to acknowledge Slovenian Research Agency (research programs P1-0021 and P2-150), Slovenia and the European Regional Development Fund within the Operational Program Science and Education for Smart Growth 2014-2020 under the Project Center of Excellence: National center of mechatronics and clean technologies-BG05M2OP001-1.001-0008, Bulgaria. The SEM and nitrogen physisorption analyses were done by Mojca Opresnik and the XRD measurements by Edi Krajnc, both from the National Institute of Chemistry, Ljubljana, for that we are very grateful.

Conflicts of Interest: The authors declare no conflict of interest.

\section{References}

1. European Environment Agency. European Topic Centre on Air Pollution and Climate Change Mitigation (ETC/ACM) Air Quality in Europe: 2017 Report; Publications Office of the European Union: Luxembourg, 2017; ISBN 978-92-9213-921-6.

2. Tomatis, M.; Xu, H.-H.; He, J.; Zhang, X.-D. Recent Development of Catalysts for Removal of Volatile Organic Compounds in Flue Gas by Combustion: A Review. J. Chem. 2016, 2016, 1-15. [CrossRef]

3. Ojala, S.; Pitkäaho, S.; Laitinen, T.; Niskala Koivikko, N.; Brahmi, R.; Gaálová, J.; Matejova, L.; Kucherov, A.; Päivärinta, S.; Hirschmann, C.; et al. Catalysis in VOC Abatement. Top. Catal. 2011, 54, 1224-1256. [CrossRef]

4. Huang, H.; Xu, Y.; Feng, Q.; Leung, D.Y.C. Low Temperature Catalytic Oxidation of Volatile Organic Compounds: A Review. Catal. Sci. Technol. 2015, 5, 2649-2669. [CrossRef]

5. Li, W.B.; Wang, J.X.; Gong, H. Catalytic Combustion of VOCs on Non-Noble Metal Catalysts. Catal. Today 2009, 148, 81-87. [CrossRef]

6. Chen, Z.W.; Chen, L.X.; Yang, C.C.; Jiang, Q. Atomic (Single, Double, and Triple Atoms) Catalysis: Frontiers, Opportunities, and Challenges. J. Mater. Chem. A 2019, 7, 3492-3515. [CrossRef]

7. Liu, W.-J.; Qian, T.-T.; Jiang, H. Bimetallic Fe Nanoparticles: Recent Advances in Synthesis and Application in Catalytic Elimination of Environmental Pollutants. Chem. Eng. J. 2014, 236, 448-463. [CrossRef]

8. Gawande, M.B.; Goswami, A.; Felpin, F.-X.; Asefa, T.; Huang, X.; Silva, R.; Zou, X.; Zboril, R.; Varma, R.S. Cu and Cu-Based Nanoparticles: Synthesis and Applications in Catalysis. Chem. Rev. 2016, 116, 3722-3811. [CrossRef] [PubMed]

9. Konsolakis, M.; Carabineiro, S.A.C.; Marnellos, G.E.; Asad, M.F.; Soares, O.S.G.P.; Pereira, M.F.R.; Órfão, J.J.M.; Figueiredo, J.L. Volatile Organic Compounds Abatement over Copper-Based Catalysts: Effect of Support. Inorg. Chim. Acta 2017, 455, 473-482. [CrossRef]

10. Popova, M.; Ristić, A.; Lazar, K.; Maučec, D.; Vassileva, M.; NovakTušar, N. Iron-Functionalized Silica Nanoparticles as a Highly Efficient Adsorbent and Catalyst for Toluene Oxidation in the Gas Phase. ChemCatChem 2013, 5, 986-993. [CrossRef]

11. Djinović, P.; Ristić, A.; Žumbar, T.; Dasireddy, V.D.B.C.; Rangus, M.; Dražić, G.; Popova, M.; Likozar, B.; Zabukovec Logar, N.; Novak Tušar, N. Synergistic Effect of CuO Nanocrystals and Cu-Oxo-Fe Clusters on Silica Support in Promotion of Total Catalytic Oxidation of Toluene as a Model Volatile Organic Air Pollutant. Appl. Catal. B Environ. 2020, 268, 118749. [CrossRef]

12. Taylor, S.H.; Heneghan, C.S.; Hutchings, G.J.; Hudson, I.D. The Activity and Mechanism of Uranium Oxide Catalysts for the Oxidative Destruction of Volatile Organic Compounds. Catal. Today 2000, 59, 249-259. [CrossRef]

13. Antunes, A.P.; Ribeiro, M.F.; Silva, J.M.; Ribeiro, F.R.; Magnoux, P.; Guisnet, M. Catalytic Oxidation of Toluene over CuNaHY Zeolites: Coke Formation and Removal. Appl. Catal. B Environ. 2001, 33, 149-164. [CrossRef]

14. Li, X.; Wang, L.; Xia, Q.; Liu, Z.; Li, Z. Catalytic Oxidation of Toluene over Copper and Manganese Based Catalysts: Effect of Water Vapor. Catal. Commun. 2011, 14, 15-19. [CrossRef]

15. Xue, T.; Li, R.; Gao, W.; Gao, Y.; Wang, Q.; Umar, A. Preparation and Characterization of Highly Efficient CuFe Mixed Oxides for Total Oxidation of Toluene. J. Nanosci. Nanotechnol. 2018, 18, 3381-3386. [CrossRef]

16. Kim, S.C.; Park, Y.-K.; Nah, J.W. Property of a Highly Active Bimetallic Catalyst Based on a Supported Manganese Oxide for the Complete Oxidation of Toluene. Powder Technol. 2014, 266, 292-298. [CrossRef]

17. Wang, C.-H. Al2O3-Supported Transition-Metal Oxide Catalysts for Catalytic Incineration of Toluene. Chemosphere 2004, 55, 11-17. [CrossRef] [PubMed]

18. Esmaeilirad, M.; Zabihi, M.; Shayegan, J.; Khorasheh, F. Oxidation of Toluene in Humid Air by Metal Oxides Supported on $\gamma$-Alumina. J. Hazard. Mater. 2017, 333, 293-307. [CrossRef] [PubMed]

19. Białas, A.; Kuśtrowski, P.; Dudek, B.; Piwowarska, Z.; Wach, A.; Michalik, M.; Kozak, M. Copper-Aluminum Oxide Catalysts for Total Oxidation of Toluene Synthesized by Thermal Decomposition of Co-Precipitated Precursors. Thermochim. Acta 2014, 590, 191-197. [CrossRef]

20. Downs, A.J. Chemistry of Aluminium, Gallium, Indium and Thallium; Springer Science \& Business Media: Glasgow, UK, 1993; Volume 111, ISBN 978-0-7514-0103-5.

21. Busca, G. Structural, Surface, and Catalytic Properties of Aluminas. Adv. Catal. 2014, 57, 319-404. [CrossRef] 
22. Trueba, M.; Trasatti, S.P. $\gamma$-Alumina as a Support for Catalysts: A Review of Fundamental Aspects. Eur. J. Inorg. Chem. 2005, 2005, 3393-3403. [CrossRef]

23. Busca, G. Catalytic Materials Based on Silica and Alumina: Structural Features and Generation of Surface Acidity. Prog. Mater. Sci. 2019, 104, 215-249. [CrossRef]

24. Wefers, K.; Misra, C. Oxides and Hydroxides of Aluminum; Alcoa Laboratories: Pittsburg, PA, USA, 1987.

25. Walker, G.S.; Pyke, D.R.; Werrett, C.R.; Williams, E.; Bhattacharya, A.K. Surface Reactivity of Aluminas Prepared by Different Techniques. Appl. Surf. Sci. 1999, 1999, 228-234. [CrossRef]

26. Lafficher, R.; Digne, M.; Salvatori, F.; Boualleg, M.; Colson, D.; Puel, F. Development of New Alumina Precipitation Routes for Catalysis Applications. J. Cryst. Growth 2017, 468, 526-530. [CrossRef]

27. Stoica, G.; Pérez-Ramírez, J. Institut Català d'Investigació Química Chemistry of Dawsonites and Application in Catalysis Doctoral Thesis; Universitat Rovira i Virgili: Tarragona, Spain, 2010; ISBN 978-84-693-1533-0.

28. Ali, A.A.; Hasan, M.A.; Zaki, M.I. Dawsonite-Type Precursors for Catalytic Al, Cr, and Fe Oxides: Synthesis and Characterization. Chem. Mater. 2005, 17, 6797-6804. [CrossRef]

29. Mosallanejad, S.; Dlugogorski, B.Z.; Kennedy, E.M.; Stockenhuber, M. On the Chemistry of Iron Oxide Supported on $\gamma$-Alumina and Silica Catalysts. ACS Omega 2018, 3, 5362-5374. [CrossRef] [PubMed]

30. Seo, C.W.; Jung, K.D.; Lee, K.Y.; Yoo, K.S. Influence of Structure Type of Al2O3 on Dehydration of Methanol for Dimethyl Ether Synthesis. Ind. Eng. Chem. Res. 2008, 47, 6573-6578. [CrossRef]

31. Laurenti, D.; Phung-Ngoc, B.; Roukoss, C.; Devers, E.; Marchand, K.; Massin, L.; Lemaitre, L.; Legens, C.; Quoineaud, A.-A.; Vrinat, M. Intrinsic Potential of Alumina-Supported CoMo Catalysts in HDS: Comparison between $\Gamma \mathrm{c}, \Gamma \mathrm{T}$, and $\delta$-Alumina. J. Catal. 2013, 297, 165-175. [CrossRef]

32. Louw, L.-A. The Synthesis of Aluminium Hydroxide and Oxyhydroxide. Ph.D. Thesis, University of Cape Town, Cape Town, South Africa, 1993.

33. Lefèvre, G.; Duc, M.; Lepeut, P.; Caplain, R.; Fédoroff, M. Hydration of $\gamma$-Alumina in Water and Its Effects on Surface Reactivity. Langmuir 2002, 18, 7530-7537. [CrossRef]

34. Xie, Y.; Kocaefe, D.; Kocaefe, Y.; Cheng, J.; Liu, W. The Effect of Novel Synthetic Methods and Parameters Control on Morphology of Nano-Alumina Particles. Nanoscale Res. Lett. 2016, 11. [CrossRef]

35. Thommes, M.; Kaneko, K.; Neimark, A.V.; Olivier, J.P.; Rodriguez-Reinoso, F.; Rouquerol, J.; Sing, K.S.W. Physisorption of Gases, with Special Reference to the Evaluation of Surface Area and Pore Size Distribution (IUPAC Technical Report). Pure Appl. Chem. 2015, 87, 1051-1069. [CrossRef]

36. Bordiga, S.; Buzzoni, R.; Geobaldo, F.; Lamberti, C.; Giamello, E.; Zecchina, A.; Leofanti, G.; Petrini, G.; Tozzola, G.; Vlaic, G. Structure and Reactivity of Framework and Extra-Framework Iron in Fe-Silicalite as Investigated by Spectroscopic and Physicochemical Methods. J. Catal. 1996, 158, 486-501. [CrossRef]

37. Chmielarz, L.; Kuśtrowski, P.; Dziembaj, R.; Cool, P.; Vansant, E.F. Catalytic Performance of Various Mesoporous Silicas Modified with Copper or Iron Oxides Introduced by Different Ways in the Selective Reduction of NO by Ammonia. Appl. Catal. B Environ. 2006, 62, 369-380. [CrossRef]

38. Sun, Y.; Tian, P.; Ding, D.; Yang, Z.; Wang, W.; Xin, H.; Xu, J.; Han, Y.-F. Revealing the Active Species of Cu-Based Catalysts for Heterogeneous Fenton Reaction. Appl. Catal. B Environ. 2019, 258, 117985. [CrossRef]

39. Pérez-Ramírez, J.; Santhosh Kumar, M.; Brückner, A. Reduction of $\mathrm{N}_{2} \mathrm{O}$ with CO over FeMFI Zeolites: Influence of the Preparation Method on the Iron Species and Catalytic Behavior. J. Catal. 2004, 223, 13-27. [CrossRef]

40. Xin, Q.; Glisenti, A.; Philippopoulos, C.; Poulakis, E.; Mertens, M.; Nyalosaso, J.; Meynen, V.; Cool, P. Comparison between a Water-Based and a Solvent-Based Impregnation Method towards Dispersed CuO/SBA-15 Catalysts: Texture, Structure and Catalytic Performance in Automotive Exhaust Gas Abatement. Catalysts 2016, 6, 164. [CrossRef]

41. Lamberti, C.; Bordiga, S.; Salvalaggio, M.; Spoto, G.; Zecchina, A.; Geobaldo, F.; Vlaic, G.; Bellatreccia, M. XAFS, IR, and UV- Vis Study of the CuI Environment in CuI-ZSM-5. J. Phys. Chem. B 1997, 101, 344-360. [CrossRef]

42. Taifan, W.E.; Li, Y.; Baltrus, J.P.; Zhang, L.; Frenkel, A.I.; Baltrusaitis, J. Operando Structure Determination of Cu and Zn on Supported $\mathrm{MgO} / \mathrm{SiO} 2$ Catalysts during Ethanol Conversion to 1,3-Butadiene. ACS Catal. 2019, 9, 269-285. [CrossRef]

43. Acikgoz, M.; Khoshi, M.R.; Harrell, J.; Genova, A.; Chawla, R.; He, H.; Pavanello, M. Tuning the Electronic Properties of the $\gamma$-Al2O3 Surface by Phosphorus Doping. Phys. Chem. Chem. Phys. 2019, 21, 15080-15088. [CrossRef]

44. Boumaza, A.; Favaro, L.; Lédion, J.; Sattonnay, G.; Brubach, J.B.; Berthet, P.; Huntz, A.M.; Roy, P.; Tétot, R. Transition Alumina Phases Induced by Heat Treatment of Boehmite: An X-ray Diffraction and Infrared Spectroscopy Study. J. Solid State Chem. 2009, 182, 1171-1176. [CrossRef]

45. Zhang, Y.C.; Tang, J.Y.; Wang, G.L.; Zhang, M.; Hu, X.Y. Facile Synthesis of Submicron $\mathrm{Cu}_{2} \mathrm{O}$ and CuO Crystallites from a Solid Metallorganic Molecular Precursor. J. Cryst. Growth 2006, 294, 278-282. [CrossRef]

46. Stoica, G.; Abelló, S.; Pérez-Ramírez, J. Na-Dawsonite Derived Aluminates for DMC Production by Transesterification of Ethylene Carbonate. Appl. Catal. Gen. 2009, 365, 252-260. [CrossRef]

47. Rinaldi, R.; Schuchardt, U. On the Paradox of Transition Metal-Free Alumina-Catalyzed Epoxidation with Aqueous Hydrogen Peroxide. J. Catal. 2005, 236, 335-345. [CrossRef]

48. Samain, L.; Jaworski, A.; Edén, M.; Ladd, D.M.; Seo, D.-K.; Javier Garcia-Garcia, F.; Häussermann, U. Structural Analysis of Highly Porous $\gamma-\mathrm{Al}_{2} \mathrm{O}_{3}$. J. Solid State Chem. 2014, 217, 1-8. [CrossRef] 
49. Chandran, C.V.; Kirschhock, C.E.A.; Radhakrishnan, S.; Taulelle, F.; Martens, J.A.; Breynaert, E. Alumina: Discriminative Analysis Using 3D Correlation of Solid-State NMR Parameters. Chem. Soc. Rev. 2019, 48, 134-156. [CrossRef] [PubMed]

50. He, C.; Cheng, J.; Zhang, X.; Douthwaite, M.; Pattisson, S.; Hao, Z. Recent Advances in the Catalytic Oxidation of Volatile Organic Compounds: A Review Based on Pollutant Sorts and Sources. Chem. Rev. 2019, 119, 4471-4568. [CrossRef]

51. Lee, J.; Jang, E.J.; Kwak, J.H. Acid-Base Properties of Al2O3: Effects of Morphology, Crystalline Phase, and Additives. J. Catal. 2017, 345, 135-148. [CrossRef] 